\title{
NBSIR 73-175 \\ Estimates of Vehicular Collisions with Multistory Residential Buildings
}

Stuart L. Fribush

Deborah Bowser

Robert Chapman

Technical Analysis Division

National Bureau of Standards

Washington, D. C. 20234

April 1973

Final Report

Prepared for

Office of Policy Development $\&$ Research

Department of Housing and Urban Development

Washington, D. C. 20410 


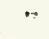

.

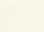

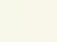

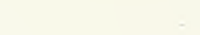

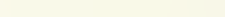

(2) 
NBSIR 73-175

\section{ESTIMATES OF VEHICULAR COLLISIONS WITH MULTISTORY RESIDENTIAL BUILDINGS}

Stuart L. Fribush

Deborah Bowser

Robert Chapman

Technical Analysis Division

National Bureau of Standards

Washington, D. C. 20234

April 1973

Final Report

Prepared for

Office of Policy Development \& Research

Department of Housing and Urban Development

Washington, D. C. 20410

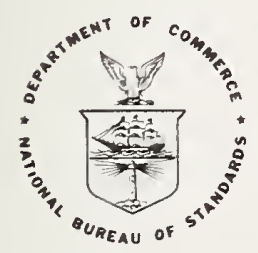

U. S. DEPARTMENT OF COMMERCE, Frederick B. Dent, Secretary NATIONAL BUREAU OF STANDARDS, Richard W. Roberts, Director 



\section{List of Figures}

Figure 2.1 Set Theory Interpretation of Building Collision Accidents

Figure 2.2 Highway Accidents in U.S. 1967-71

Figure 2.3 Runoff Accidents in U.S. 1967-71

Figure A.l Runoff Accidents by Location

Figure A.2 Frequency of Collision vs. Dollar Damage to Building

Figure A.3 Frequency of Collision vs. Speed at Impact

Figure A.4 Highway Classification for Runoff Accidents

Figure A.5 Frequency of Truck Accidents in Built-up Areas vs. Speed

Figure A.6 Truck Accidents vs. Type of Truck

Figure B.I Building Collision Accidents by Road Type Figure B.2 Building Collision Accidents by Population Figure B.3 Building Collision Accidents by Vehicle Type Figure B.4 Building Collision Accidents by Dollar Damage 

TABLE OF CONTENTS

SUMMARY

1.0 INTRODUCTION

2.0 NATIONAL FORECASTS OF BUILDING COLLISION ACCIDENTS

2.1 Introduction

2. 2 Propcrtionality Model

2.3 Regression Model

2.3.1 Theoretical Development

2.3.2 Model Input

2.3.3 Model Output

2.3.4 Model Extensions

2.4 Discussions

2. 5 Chapter Summary

APPENDIX A - OKLAHOMA VEHICULAR IMPACT ANALYSIS

A. 1 Introduction

A. 2 Analysis

A. 3 Summary

APPENDIX B - ILLINOIS VEHICULAR IMPACT ANALYSIS

B.1 Introduction

B. 2 Analysis

B.2.1 Building Collision Accidents by Road Type

B.2.2 Building Collision Accidents by Population

B.2.3 Building Collision Accidents by Vehicle Type

B.2.4 Building Collision Accidents by Dollar Damage to Property

B.2.5 Building Collision Accidents by

B. 3 Summary Driving Conditions

APPENDIX C - MULTISTORY RESIDENTIAL BUILDINGS

APPENDIX D - MOTOR VEHICLE REGISTRATIONS 1960-1970 

Table 2.I National Motor Vehicle Accident Data

Table 2.2 Regression Results

Table 2.3 Estimated Building Collision Accidents

Table 2.4 Estimates for BC(US) for 1970 and Values of $(\mathrm{BC} / \mathrm{RO})$ for 1970 .

Table 2.5 Estimated Building Collision Accidents Resulting in Substantial Damage to Multi-story Residential structures

Table A.I Group A Sumnary

Table A.2 Group B Summary

Table B.I Distribution of Building Collision Accidents by Number of Vehicles Involved

Table B.2 Summary Comparison: Maximum Damage Building Collision Accidents vs. All Building Collision Accidents

Table C.I 1970 Housing Data

Table C.2 1960 Housing Data

Table C.3 Summary Comparison of Housing Data 1960-1970

Table D.l Motor Vehicle Registrations

Table D.2 Growth of Motor Vehicle Registrations 1960-1970

Table D.3 Motor Vehicle Registrations in U. S. 1965-1970 



\section{SUMMARY}

This study was designed to investigate the frequency with which motor vehicles collide with buildings in the United states. In particular, the objective was to assess the extent to which motor vehicles collide with multistory* residential buildings, potentially causing substantial damage. It was soon discovered that statistics for "building collision" accidents are not available on a national level; data therefore had to be drawn from state motor vehicle accident records. Two states, Oklahoma and Illinois, provided data on accidents which occurred within their respective jurisdictions in 1970. In general, it was learned that "building collision" accidents are largely the result of single vehicles running off the road in urban areas.

National estimates of "building collision" accidents have been generated, with information extracted from the Oklahoma and Illinois analyses as inputs. It is estimated that the annual number of "building collision" accidents which occur nationally is of the order of twenty to forty thousand. However, when this estimate is modified to account for only those accidents causing substantial damage to multistory residential buildings, the magnitude is then decreased by roughly a thousandfold. Therefore, an estimated value for the number of vehicles colliding with multistory residential

Multistory here means buildings with four or more floors. 
buildings and causing substantial damage in 1970 is of the order of 40. The annual probability of a given building being affected by such an accident was approximately one in ten thousand. A discussion then follows on existing data collection systems which might be modified to provide better estimates of the number of "building collision" accidents. 
1.0 Introduction

Since 1968 there has been growing international concern that buildings, particularly multistory residential buildings, may be subjected to loading conditions not normally considered in design, i.e., abnormal loadings. In that year there occurred the much-publicized collapse of an apartment house at Ronan Point in England. In this 22-story building of precast concrete panel construction, collapse was triggered by an accidental explosion of gas that leaked from the connection of a gas range located in an apartment on the 18 th floor. As a result of the explosion, one corner of the building collapsed for the height of the apartment unit.

In November 1971, the Department of Housing and Urban Development requested the National Bureau of Standards to make a study of all aspects of abnormal loading and the problem of progressive collapse. The recognized sources of abnormal loading are discussed elsewhere.* Several of these types of loading were considered to have a frequency of occurrence large enough to warrant particular attention. The collision of motor vehicles with a building is one of these. In an attempt to assess the probability of vehicular collisions with building that might be structurally

\footnotetext{
*Somes, N. F., Abnormal Loadings on Buildings and Progressive Collapse, Building Practices for Disaster Mitigation, Building Science Series 46, January, 1973.
} 
significant, this study of related U. S. statistics was initiated. The interpretation of these statistics with regard to design against progressive collapse is beyond the scope of this report.

There are essentially two classes of accidents, namely (a) those involving a vehicle within its normal operating domain (i.e., an automobile in a parking garage) and (b) those accidents that occur as a result of a vehicle leaving its normal operating path or domain (i.e., an automobile leaving a roadway and colliding with a building). This report discusses only the latter type of accident.

In order to ascertain damage done to buildings as a result of vehicular impact, detailed accident records must be examined. Probably the best source of such information would be records maintained by insurance companies. An attempt was made to obtain such records, but this did not meet with any success.

It was then decided that motor vehicle accident records would be the next best available source for the information desired. Ideally, nationwide data should be used since one of the objectives is to obtain a. national estimate of the frequency with which motor vehicles collide with buildings. However, neither the National Safety Council nor the National Transportation Sarety Board maintain statistics regarding those accidents where motor vehicles have collided with buildings ("building collisions"). 
Apparently, the reason no national statistics exist is that not all states maintain records of "building collision" accidents. However, two states which do keep records of sufficient accuracy and detail to meet the purposes of this study are Oklahoma and Illinois. Both states graciously consented to provide any available information regarding 1970 motor vehicle accidents involving "building collisions." This information was used as the starting point for the analysis. The details of the Oklahoma and Illinois analyses appear in Appendices $A$ and $B$, respectively. In Chapter 2, some crude estimates of national building collision accidents are made using information gained from the oklahoma and Illinois studies. 
2.0 National Forecasts of Building Collision Accidents

2.1 Introduction

In this chapter, two methods are described and used to obtain rough estimates of the incidence of vehicular collisions with buildings on a national scale. The first of these is a simple proportionality model which assumes that "building collision" accidents are proportional to either motor vehicle registrations or population. This method estimates only the gross number of "building collisions" and makes no attempt to account for either the type of building struck or the degree of damage caused. The second method uses linear regression to project "building collisions" based on historical accident data. This method is then modified to account for only those accidents which cause substantial damage to multistory residential buildings. Although both methods are first efforts based on scant data, they provide a perspective on the magnitude of "building collision" accidents on a national level.

2.2 Proportionality Method.

The underlying assumption on which this method is based is simply that the number of "building collision" accidents which occur in a given area is directly proportional to the motor vehicle registrations (population) in that area. It then becomes possible to estimate the total number of "building collisions" which take place throughout the United States (US) by means of extrapolation, as shown below: 
$\frac{B C \text { (US) }}{M V \text { (US) }}=\frac{B C \text { (sample) }}{M V}$

where $B C$ denotes building collisions and MV denotes motor vehicle registrations.

Assuming that BC (sample), MV (sample), and MV (US) are available, the calculation of $B C$ (US) then becomes obvious.

Using the same proportionality technique, similar

estimates can be made separately for urban and rural

building collisions:

$$
\frac{\mathrm{BC}^{\mathrm{U}} \text { (US) }}{\mathrm{MV}^{\mathrm{U}} \text { (US) }}=\frac{\mathrm{BC}^{\mathrm{U}} \text { (sample) }}{\mathrm{MV}^{\mathrm{U}} \text { (sample) }}
$$

where the superscript denotes urban.

The rural estimate is obtained as follows:

$$
\frac{B C^{R} \text { (US) }}{M V^{R} \text { (US) }}=\frac{B C^{R} \text { (sample) }}{M V^{R} \text { (sample) }}
$$

where the superscript denotes rural.

The sample available for this study consists of the traffic accident records of Oklahoma and Illinois. Details of the accident records are provided in Appendix $A$ and $B$ respectively with the most relevant statistics summarized below.

Total "Building Collision" Accidents in 1970

$$
\begin{gathered}
\text { Oklahoma } \\
\text { Illinois - } 50 \\
\text { Total - } 1229 \\
\hline
\end{gathered}
$$


*Urban "Building Collision" Accidents in 1970

$$
\begin{aligned}
& \text { Oklahoma - } 34 \\
& \text { Illinois - } 1137
\end{aligned}
$$

*Rural "Building Collision" Accidents in 1970

$$
\begin{array}{ll}
\text { Oklahoma - } & 16 \\
\text { Illinois - } & 92
\end{array}
$$

Using the Oklahoma data on total motor vehicle registrations* we obtain estimates for the Building Collisions (US) to be 3200 . Using Illinois data we obtain the estimate 25,000. Since the collision data for Illinois does not include all of the Chicago data, this last estimate should be revised upward. Note that these estimates are about an order of magnitude apart, so we are in an unfortunate position. If one could assume that the Oklahoma estimate was a representative low one and the Illinois estimate a representative high one, then a pooling of the data (giving equal weight to each) would yield an estimate of about 20,000.

*The numbers for rural and urban "building collision" accidents in Oklahoma and IIIinois do not correspond to the numbers given in the summaries of Appendices $A$ and $B$ because of a difference in the definition of urban. In Appendices $A$ and $B$ municipalities of over 5,000 population were considered urban. However, the Bureau of the Census uses a breakpoint of 2,500 to distinguish between urban and rural. Hence the urban and rural population figures needed in this proportionality analysis are based on this breakpoint. Therefore, the sample "building collision" accident figures were adjusted to correspond to a population breakpoint of 2,500 . **See Table D.1, page 64. 
If one were to employ population in place of motor vehicle registrations, one would obtain from the pooled data for Oklahoma and Illinois that $B C(U S) \simeq 19,000$, $\mathrm{BC}^{\mathrm{U}}(\mathrm{US}) \simeq 16,000$ while $\mathrm{BC}^{\mathrm{R}}(\mathrm{US}) \simeq 3,000$. Both the urban and total us values are smaller than they should be because of the unrecorded Chicago collisions.

The population statistics needed for the analysis are given below.*

Total Population 1970

$$
\begin{aligned}
& \text { U.S. } \\
& \text { Oklahoma - } 203.2 \times 10^{6} \\
& \text { Illinois - } 11.1 \times 10^{6} \times 10^{6}
\end{aligned}
$$

Urban Population 1970 (municipalities 22,500 )

$$
\begin{aligned}
& \text { U.S. } \\
& \text { Oklahoma - } 149.3 \times 10^{6} \\
& \text { Illinois - } 9.2 \times 10^{6}
\end{aligned}
$$

Rura 1 Population 1970

$$
\begin{aligned}
& \text { U.S. } \\
& \text { Oklahoma - } 53.9 \times 10^{6} \\
& \text { Illinois - } 1.9 \times 10^{6}
\end{aligned}
$$

Certainly the BC(US) is greater than 1279, the total of those in Oklahoma and Illinois. If we consider the states with high motor vehicle registrations, like New York, New Jersey, Pennsylvania, Ohio, California, et cetera, a reasonable bound for building collisions in the United States might be on the order of 10,000 .

* Taken from Statistical Abstracts of the United States 1971, Table 17. 
These admittedly crude estimates are useful in providing insight as to the order of magnitude for the number of buildings struck by vehicles per year. Thus the above estimates suggest that the annual number of vehicular collisions with buildings is on the order of tens of thousands and possibly near 20,000. However, there are other means of obtaining estimates which may prove more reliable.

2.3 Regression Model

2.3.1 Theoretical Development

Before introducing this model it may be instructive to review the necessary antecedent conditions for "building collision" accidents. An obvious major prerequisite is that the vehicle first runs off the road. Therefore, the set of all "building collision" accidents is a subset of the set of all runoff accidents. Similarly, the set of all runoff accidents is a subset of the set of all motor vehicle accidents. This relationship is depicted schematically in figure 2.1.

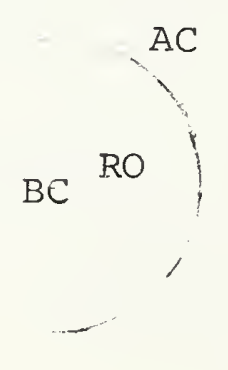

$$
\begin{aligned}
A C= & \text { All Motor } \\
& \text { Vehicle } \\
& \text { Accidents } \\
R O= & \text { Runoffs } \\
B C= & \text { Building } \\
& \text { Collisions }
\end{aligned}
$$

Figure 2.1

SET THEORY REPRESENTATION OF BUILDING COLLISION ACCIDENTS 
Mathematically, this relationship can be represented in terms of frequency ratios as follows:

$$
\frac{N(B C)}{N(A C)}=\frac{N(B C)}{N(R O)} \times \frac{N(R O)}{N(A C)}
$$

where $N()$ denotes the number of the expression in (). If one denotes these numbers simply as $B C, A C, \ldots$ then we can write

$$
B C=(A C)(R O / A C) \quad(B C / R O)
$$

that is, the total number of "building collisions" is equal to the total number of vehicle accidents multiplied by the proportion of accidents which are run-off times the proportion of "building collisions" to run-offs.

From the Oklahoma and Illinois studies (Appendices A and $B$ respectively), it was learned that rural "building collision" accidents and urban "building collision" accidents are really two different phenomena. In rural areas, the probability of runoff is relatively high while the probability of colliding with a building, given a runoff, is low. Conversely, in urban areas the probability of vehicular runoff is low, but the probability of vehicular collision with a building given a runoff, is relatively high. This suggests that an estimation model for the number of "building collisions" should have both urban and rural components. Therefore: 
Table 2.1. National Motor Vehicle Accident Data

\begin{tabular}{|c|c|c|c|c|}
\hline & $\begin{array}{l}\text { All } \\
\text { Accidents } \\
\text { URBAN }\left(10^{6}\right)\end{array}$ & $\begin{array}{l}\text { All } \\
\text { Accidents } \\
\text { RURAL }\left(10^{6}\right)\end{array}$ & $\begin{array}{l}\left(\frac{\mathrm{RO}}{\mathrm{AC}}\right) \% \\
\text { URBAN }\end{array}$ & $\begin{array}{l}\left(\frac{\mathrm{RO}}{\overline{\mathrm{AC}}}\right) \% \\
\text { RURAI }\end{array}$ \\
\hline 1967 & 9.8 & 3.9 & 4.9 & 27.3 \\
\hline 1968 & 10.4 & 4.2 & 5.7 & 27.3 \\
\hline 1969 & 11.1 & 4.4 & 4.8 & 30.2 \\
\hline 1970 & 11.5 & 4.5 & 4.9 & 29.4 \\
\hline 1971 & 11.8 & 4.6 & 4.9 & 29.4 \\
\hline
\end{tabular}

*Taken from Accident Facts, published by the National Safety Council, Chicago, Illinois, 1968-1972. 


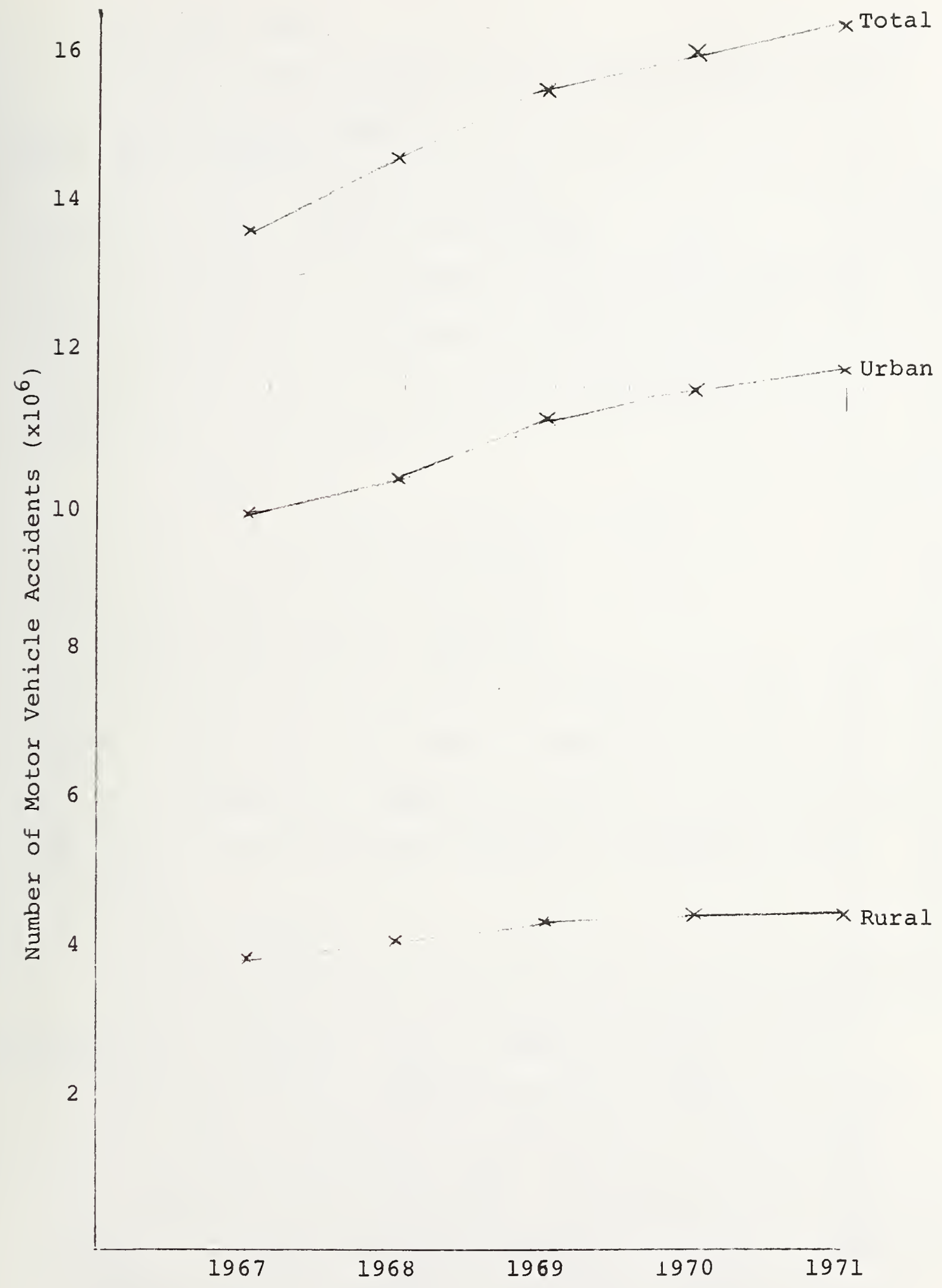

Figure 2.2 Highway Accidents in U. S. 1967-1971. 


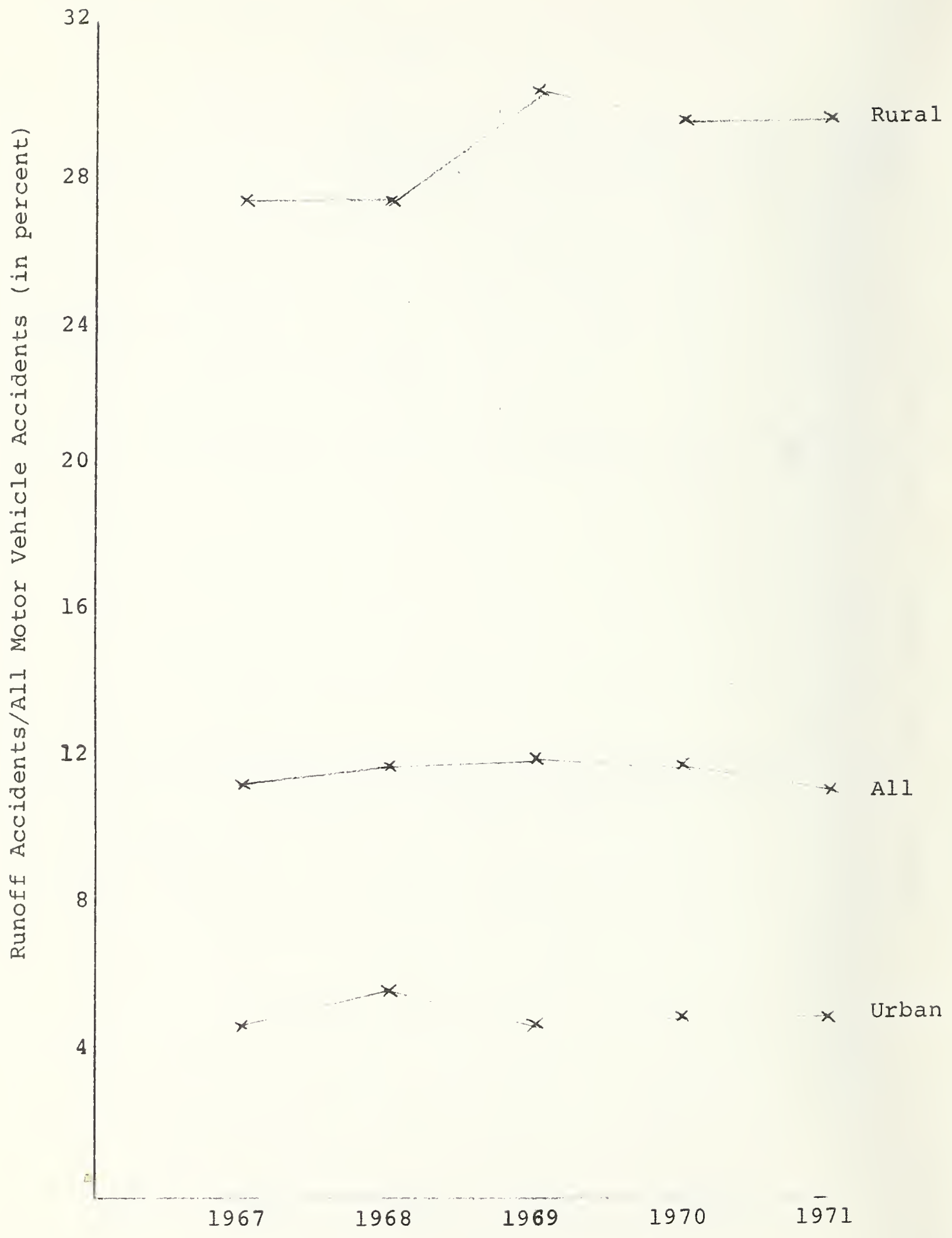

Figure 2.3 Runoff Accidents in U. S. 1967-1971. 
$B C=B C^{U}+B C^{R}$

where the superscripts $U$ and $R$ refer to urban and

rural respectively

$B C^{U}=(A C)^{U}(R O / A C)^{U}(B C / R O)^{U}$

and $B C^{\mathrm{R}}=(\mathrm{AC})^{\mathrm{R}}(\mathrm{RO} / \mathrm{AC})^{\mathrm{R}}(\mathrm{BC} / \mathrm{RO})^{\mathrm{R}}$

If this model is intended for use in the prediction of future occurrences of "building collision" accidents, it is necessary to include a time factor in the model. This requirement is indicated by:

$B C_{t}=B C_{t}^{U}+B C_{t}^{R}$

where the subscript $t$ denotes the year

and $B C_{t}^{U}=(A C)_{t}^{U}(R O / A C)_{t}^{U}(B C / R O){ }_{t}^{U}$

$B C_{t}^{R}=(A C)_{t}^{R}(R O / A C)_{t}^{R}(B C / R O)_{t}^{R}$

Equations 9-11 constitute the prediction model. The terms on the right hand sides of equations (10) and (11) must now be estimated for future years. The following section deals with the methodology employed in generating such estimates.

\subsubsection{Model Input}

The National Safety Council maintains annual national statistics regarding both the number of motor vehicle accidents and the percentage of those accidents which were runoffs. This information is available for 1967 through 1971, and is shown in table 2.1. Figures 2.2 and 2.3 provide general representations of the data in table 2.1. In general, it appears that the number of motor vehicle accidents has 
increased over time (figure 2.2), while the percentage of accidents which are runoffs has remained relatively constant (figure 2.3). Simple linear regression was applied to the 4 columns in table 2.1 , using time as the independent variable to test the hypotheses stated above. The values of time ( $t$ ) used in the analysis were the last two digits of the year in question $(67,68, \ldots 71)$. Also, the number of accidents is predicted in millions, while the proportion of runoffs is predicted in percent. The results of the analysis appear in table 2.2 .

Table 2.2. REGRESSION RESULTS

$\begin{array}{llllll}\text { (1) All Urban } & -24.27 & .51 & .975 & >.995 \\ \text { (2) All Rural } & -7.41 & .17 & .938 & >.995 \\ \text { (3) 8RO Urban } & 10.56 & -.08 & .116 & <.95 \\ \text { (4) 8RO Rural } & -14.75 & .63 & .555 & <.95\end{array}$

${ }^{*} R^{2}$, the square of the correlation coefficients, is a simple measure of the degree of goodness of fit between the input data and the calculated regression line. An $R^{2}$ equal to $l$ indicates perfect fit and any $R^{2}$ greater than 0.9 is considered to be a good fit. The use of $R^{2}$ does not imply in any way that time itself is a determinant of accident behavior, however.

**Pi(t) refers to the percentage point of a student's-t distribution with 3 degrees of freedom corresponding to the ratio of the slope of calculated regression line to its estimated standard deviation. 
The high levels of $R^{2}$, for rows 1 and 2 of table 2.2 indicate that the regression lines are good estimators of both $(A C)_{t}^{R}$ and $(A C)_{t^{\prime}}^{U}$ at least over a short period of time. student's-ttests were applied to the estimates of the slopes of the lines in rows 1 and 2 in order to test the hypotheses that the slopes could be zero. The results of the t-tests indicate that the hypotheses that the slopes are zero must be rejected at the 99.58 confidence level. Therefore, the best estimates for $(A C)_{t}^{U}$ and $(A C)_{t}^{R}$ are the following:

$$
\begin{aligned}
& (A C)_{t}^{U}=(-24.27+.51 t) 10^{6} \quad t=70,71 \ldots \\
& (\mathrm{AC})_{t}^{\mathrm{R}}=(-7.41+.17 t) 10^{6} \quad t=70,71 \ldots
\end{aligned}
$$

Unfortunately, the regression results for $(R O / A C)_{t}^{U}$ and $(\mathrm{RO} / \mathrm{AC})_{t}^{R}$ were not as significant. The relatively low levels of $\mathrm{R}^{2}$ in rows 3 and 4 of table 2.2 indicate a poor correlation. In addition, applying t-tests to the estimates of the slopes in rows 3 and 4 reveals that the hypotheses that the slopes are zero cannot be rejected at the $95 \%$ level. Therefore, it is not unreasonable to assume that $(\mathrm{RO} / \mathrm{AC})_{t}^{\mathrm{U}}$ and $(\mathrm{RO} / \mathrm{AC})_{t}^{\mathrm{R}}$ remain constant over time. For modeling purposes, then, $(\mathrm{RO} / \mathrm{AC})_{t}^{U}$ and $(\mathrm{RO} / \mathrm{AC})_{t}^{R}$ will be set equal to the means of $(\mathrm{RO} / \mathrm{AC})_{t}^{\mathrm{U}}$ and $(\mathrm{RO} / \mathrm{AC})_{t}^{\mathrm{R}}$ from 1967 through 1971:

$$
\begin{aligned}
& (\mathrm{RO} / \mathrm{AC})_{t}^{U}=.05 \text { for all } t \\
& (\mathrm{RO} / \mathrm{AC})_{t}^{\mathrm{R}}=.29 \text { for all } t
\end{aligned}
$$


Unfortunately, the National Safety Council does not maintain statistics regarding building collision accidents. Estimates for $(B C / R O)_{t}^{U}$ and $(B C / R O)_{t}^{R}$ have therefore been obtained from the information gathered from oklahoma and Illinois. Since only 1970 data was gathered, the estimates of $(B C / R O)_{t}^{U}$ and $(B C / R O)_{t}^{R}$ were, of necessity, point estimates. At this point we can digress and check the estimates for the year 1970. Here the national $A C$ and (RO/AC) figures are known while the $(B C / R O)$ values are known only for Oklahoma and Illinois. Using these cata one generates the estimates for 1970 in Table 2.3.

Table 2.3 ESTIMATES FOR BC(US) FOR 1970 AND VALUES OF (BC/RO) FOR 1970.

\begin{tabular}{|c|c|c|c|c|c|c|c|}
\hline \multicolumn{4}{|c|}{ BC Based on: } & \multicolumn{4}{|c|}{$\mathrm{BC} / \mathrm{RO}$ Based on: } \\
\hline & $\begin{array}{l}\text { Okla. } \\
\text { Data }\end{array}$ & $\begin{array}{l}\text { Il1. } \\
\text { Data }\end{array}$ & $\begin{array}{c}\text { Pooled } \\
\text { Data }\end{array}$ & & $\begin{array}{l}\text { Okıa. } \\
\text { Data }\end{array}$ & $\begin{array}{l}\text { Ill. } \\
\text { Data }\end{array}$ & $\begin{array}{c}\text { Pooled } \\
\text { Data }\end{array}$ \\
\hline Urban & 11800 & 27600 & 26500 & Urban & .021 & .049 & .047 \\
\hline Rural & 7300 & 14500 & 13200 & Rural & .0055 & .011 & .010 \\
\hline U. S. & 19100 & 42136 & & & - & - & - \\
\hline
\end{tabular}

It is interesting to note that using Illinois or pooled data trom Oklahoma and Illinois, one again has an estimate of about 40,000 building collision accidents for the U. S., and that the oklahoma data alone would yield an estimate of 19,100. The agreement with the estimates based on proportionality assumptions may well be fortuitous, but it is certainly not discouraging to have this agreement. 
At this point we return to the estimation of $\mathrm{BC}_{t}^{U}$ and $B C_{t}^{R}$ over time. Using the least squares linear regression for $A C_{t}^{U}$ and $A C_{t}^{R}$, and assuming that the ratios of $(R O / A C)_{t}^{U}=$ .05 and $(\mathrm{RO} / \mathrm{AC})_{t}^{\mathrm{R}}=.29$ for all times and that the ratios $(\mathrm{BC} / \mathrm{RO})_{t}^{\mathrm{U}}=.047$ and $(\mathrm{BC} / \mathrm{RO})_{t}^{\mathrm{R}}=.010$ are constant with time and equal to the pooled values for Oklahoma and Illinois for 1970 , the estimation equations reduce to:

$$
\begin{array}{ll}
B C_{t}^{U}=-57035+1199 t & \text { (Urban Component) } \\
B C_{t}^{R}=-21490+493 t & \text { (Rural Component) }
\end{array}
$$

Because of the data limitations we rounded off these equations to

$$
\begin{aligned}
& (B C)_{t}^{U}=-57000+1200 t \\
& (B C)_{t}^{R}=-21500+500 t
\end{aligned}
$$

Combining equations 18 and 19 yields a total estimate for the number of building collision accidents in a given year:

$$
\begin{aligned}
& B C_{t}=B C_{t}^{C}+B C_{t}^{R} \\
& B C_{t}=-78500+1700 t
\end{aligned}
$$$$
t=70,71 \ldots
$$

Equations 9, and 18 through 21 constitute the prediction model. In the next section the output from this model will be presented and interpreted.

2.3.3 Model Output

Table 2.4 presents the output generated by the model. 


\begin{tabular}{llll}
\hline Year & $\begin{array}{l}\text { Urban } \\
\text { Builing } \\
\text { Collisions }\end{array}$ & $\begin{array}{l}\text { Rural } \\
\text { Building } \\
\text { Collisions }\end{array}$ & Total \\
\hline 1967 & 23400 & 12000 & 35400 \\
1968 & 24600 & 12500 & 37100 \\
1969 & 25800 & 13000 & 38800 \\
1970 & 27000 & 13500 & 40500 \\
1971 & 28200 & 14000 & 42200 \\
1972 & 29400 & 14500 & 43900 \\
1973 & 30600 & 15000 & 45600 \\
1974 & 31800 & 15500 & 47300 \\
1975 & 33000 & 16000 & 49000 \\
\hline
\end{tabular}

No attempt has been made to extrapolate past $197 \mathrm{~b}$. Because of the linear nature of the estimation method, the number of building collision accidents may be expected to continue to increase at a constant rate. However, longterm extrapolation is hardly warranted considering the limitations inherent in the development of the method. The constant growth projection is essentially due to the fact that the total number of motor vehicle accidents increased at an approximately constant annual rate from 1 y67 to 1971. The magnitude of the estimates generated by the model requires further examination. Mathematically, the method is structured so that the number of building collision accidents is directly proportional to BC/RO. This implies that if, for example, the estimate of (BC/RO) $t_{t}^{U}$ were halved, 
then the resultant predictions for $B C_{t}^{U}$ would be halved for all times. The estimate for $(B C / R O){ }_{t}^{U}$ was calculated by combining both oklahoma and Illinois data. However, if only the oklahoma data had been used, the estimate would have been $32 / 1489=$ .0215. The estimate of $(B C / R O)_{t}^{U}$ used for modeling purposes may well be biased on the high side.

\subsubsection{Model Extensions}

One conclusion which can be drawn from these estimates is that, regardless of the exact proportion of runofts which result in building collisions, the number of vehicles which annually collide with buildings is on the order of tens of thousands. However, the number of accidents provides no information about either the type of building hit or the kind and amount of damage caused. One goal of this study is to assess the extent to which vehicular impact might be responsible for substantial damage to multistory residential buildings, and perhaps leading to progressive collapse. Two questions therefore, remain at issue:

(1) What proportion of "building collisions" cause substantial damage?

(2) What proportion of the substantially damaged buildings ڤn (1) are multistory residential buildings?

With regard to the first question, $\$ 1,000$ in building property damage was chosen as a convenient breakpoint which certainly eliminates non-substantial damage, although 
larger damage amounts may not be necessarily significant. Examining the Illinois and Oklahoma data, it was found that of the 1279 reported "building collision" accidents, 119 or 9.3응 had building property damage estimates of at least $\$ 1,000$. For purposes of crude estimation, it is assumed that approximately $10 \%$ of the "building collision" accidents result in substantial damage to the building.

With regard to the number of buildings which are multistory residential, rough estimates were derived from the 1970 Census of Housing. Details of the approximation appear in Appendix C. A summary follows.

In summary, there are approximately 50 million residential buildings in the United States, of which less than $1 \%$ (that is, 400,000 ) are multistory in the sense of having four or more floors above ground. It must be emphasized that the figures cited above are based entirely on housing data, with no account taken of commercial structures, for which no information was available, since earlier calculations have been based on building collisions, it can readily be seen that the multistory residential buildings must be significantly less than $1 \%$ of the total number of buildings.

Assuming that the combined oklahoma and Illinois damage distribution is somewhat representative of the nation as a whole, and that the percentage of building collision accidents which affect multistory residential buildings is 
similar to the proportion of residential structures which are multistory, then one can derive a national estimate for the number of multistory residential buildings which are likely to be affected by vehicular collision annually. This estimate is generated by using the model output described in section 2.3 .3 and adjusting it for (a) damages exceeding $\$ 1000$ and (b) multistory residential buildings. Since damages exceeding $\$ 1000$ account for 10 percent of all "building collisions," and multistory residential structures constitute approximately 1 percent of all residential buildings, estimates of the total number of motor vehicles which collide with multistory residential structures and which cause significant damage can be determined by dividing the data in table 2.4 by 1000 . Table 2.5 presents the adjusted estimates.

These admittedly crude estimates indicate that the number of vehicles colliding with multistory residential buildings and causing substantial damage is small compared to the total number of estimated "building collisions, and that the rate of increase is also relatively low. When one considers the manner in which the damage, multistory residential, and "building collision" components of the method were calculated, the entries in tabel 2.4 are felt to be on the high side. The actual number of signiticant accidents for any given year probably lies somewhere 
Table 2.5 ESTIMATED BUILDING COLLISION ACCIDENTS RESULTING IN DAMAGE TO MULTISTORY RESIDENTIAL STRUCTURES WHICH EXCEEDS \$1000.

YEAR

1967

1968

1969

1970

1971

1972

1973

1974

1975

\section{ACCIDENTS}

35

37

39

40

42

44

46

47

49

between zero and this estimated high value, implyıng that the collision of a motor vehicle with a multistory residential building and causing substantial damage to it is a relatively rare phenomenon in the United States. In fact, the annual probability of a glven multistory residential bullding being struck by a vehicle with substantial damage resulting can be crudely estimated as $40 / 400,000=0.0001$ and possibly smaller. This estımate was obtained by dividing the number of significant accidents by the number of multistory residential buildings. Unfortunately, there appears to be no readily avallable information to validate the prediction results developed and discussed above. 
In this chapter, estimates were made of the number of vehicles which collide with multistory residential bullings and cause substantial damage. These estimates were based on accident statistics maintained by the National safety Council, statistics regarding "bullding collision" accidents malntained by the states of Oklahoma and Illinois, and housing statistics mantained by the U. S. Census Bureau. However, this entire estimation procedure would not have been necessary had statistics regarding "building collision" accidents been aggregated on a national level.

Such an aggregation would naturally require that each state maintain "building collision" statistics. These statistics should include such information as already maintained by the states of Oklahoma and Illinois and detailed in Appendices $A$ and $B$, respectively. This includes information as vehicle type, road type, and locality of accident. However, in addition, such information as the type of building struck, as well as a more detailed explanation of the damage caused would be extremely useful.

If statistics concerning the number of vehicles impacting multistory residential buildings are to be gathered, the need for maintaining the type of building struck is clear. Detailed damage explanations are needed as a supplement to doilar estimates because the dollar estimates by themselves do not convey very much information with regard to the type 
of damage done. In this chapter, substantial damage was considered to be any reported damage of at least $\$ 1000$. However, there is no way of determining whether this damage is structurally significant. For example, it may be possible that in some cases, a plate glass window was shattered and the resultant damage was in excess of $\$ 1000$.

If someone is considering changes to the existing data systems, we suggest that changes along the line of the above discussion be considered. The data then could be employed in more meaningful analyses.

\subsection{Chapter Summary}

In this chapter, attempts were made to forecast the number of building structures impacted annually by motor vehicles. A crude proportionality model was established and results obtained from Oklahoma and Illinois were extrapolated for the nation as a whole. The model indicates approximately 20,000 building collision accidents for 1970, with the greater number occurring in urban areas.

An alternative model, based on regression analysis, was then developed to predict future occurrences of building collision accidents as a function of historical accident data. This model estimates rough $\perp$ y 40,000 instances of building collision accidents for 1970, of which 27,000 were urban. It is felt that these estimates may be high because of the seemingly high estimated value used for the 
proportion of urban run-offs which resulted in building collisions (as used in the second model).

The results of the second model were adjusted to consider only those cases where vehicles collided with multistory residential buildings and caused damage in excess of $\$ 1000$. It is estimated that about 40 such accidents occurred in 1970, and it is felt that this is more likely a high value than the true value. On the basis of the magnitude of the modified estimates, it is tentatively concluded that the annual probability of venicular collision with multistory building is of the order of one in ten thousand. 
Appendix A

Oklahoma Vehicular Impact Analysis

\section{A.1 Introduction}

A study of 1970 Oklahoma motor vehicle accident reports was undertaken in an attempt to determine the frequency with which motor vehicle accidents involved collision with a building, and to discover the most prevalent circumstances attendant on such a collision. Oklahoma was chosen because individual traffic accidents reports include a specific code for vehicular collision with a building and because a data tape was available.

\section{A.2 Analysis}

The data for oklahoma show a total of 65,183 motor vehicle accidents in 1970. Of these accidents, 50 were collisions with a building. The category in the Oklahoma Investigators Collision Report Coding Guide under which collision with a building occurs, is specified as "Object Struck - First Contact." Discussion with personnel of the Oklahoma Department of Public Safety indicated that a vehicle deflecting from one object (e.g., grazing a sign post or curb) and then hitting a building is not coded as hitting a building. It would probably be coded under Type of Collision as "running off road." A total or 4791 such accidents occurred. Many of the following computations were made using "run off road" data, and are noted as such. 
The data indicate that roughly $2 / 3$ of all run-off accidents occurred in non-built-up areas, where there is less chance of a building being struck. This is shown in figure A.1, which exhibits the frequency of both run-off accidents and building collision accidents by location. Most collisions with buildings caused minor dollar damage to the building, as is shown in figure A.2, a chart displaying the frequency of collision vs. property damage. By Oklahoma standards for coding, property damage refers to all property damage excluding damage to the vehicle. Figure A.3 shows the frequency of collision with buildings at various speeds of impact. Further evaluation of the data shown in these three figures yields the following:

(1) The fraction of the run-off accidents that were reported to hit a building was $50 / 4791=.0104 \simeq .010$. The average property damage when a vehicle strikes a building was $\$ 622$, and the average speed at impact was $14 \mathrm{mph}$. (2)* For non-built up areas the fraction of the run-off accidents that were reported to hit a building was $5 / 3219=.00155 \simeq .002$. Here average property damage was $\$ 800$, and the average speed at impact was $38 \mathrm{mph}$.*

The sum of accidents in built-up areas and non-built-up areas is less than the totals shown in (1) because 128 run-offs and 3 building collisions did not specify location. (See Figure A.1) 


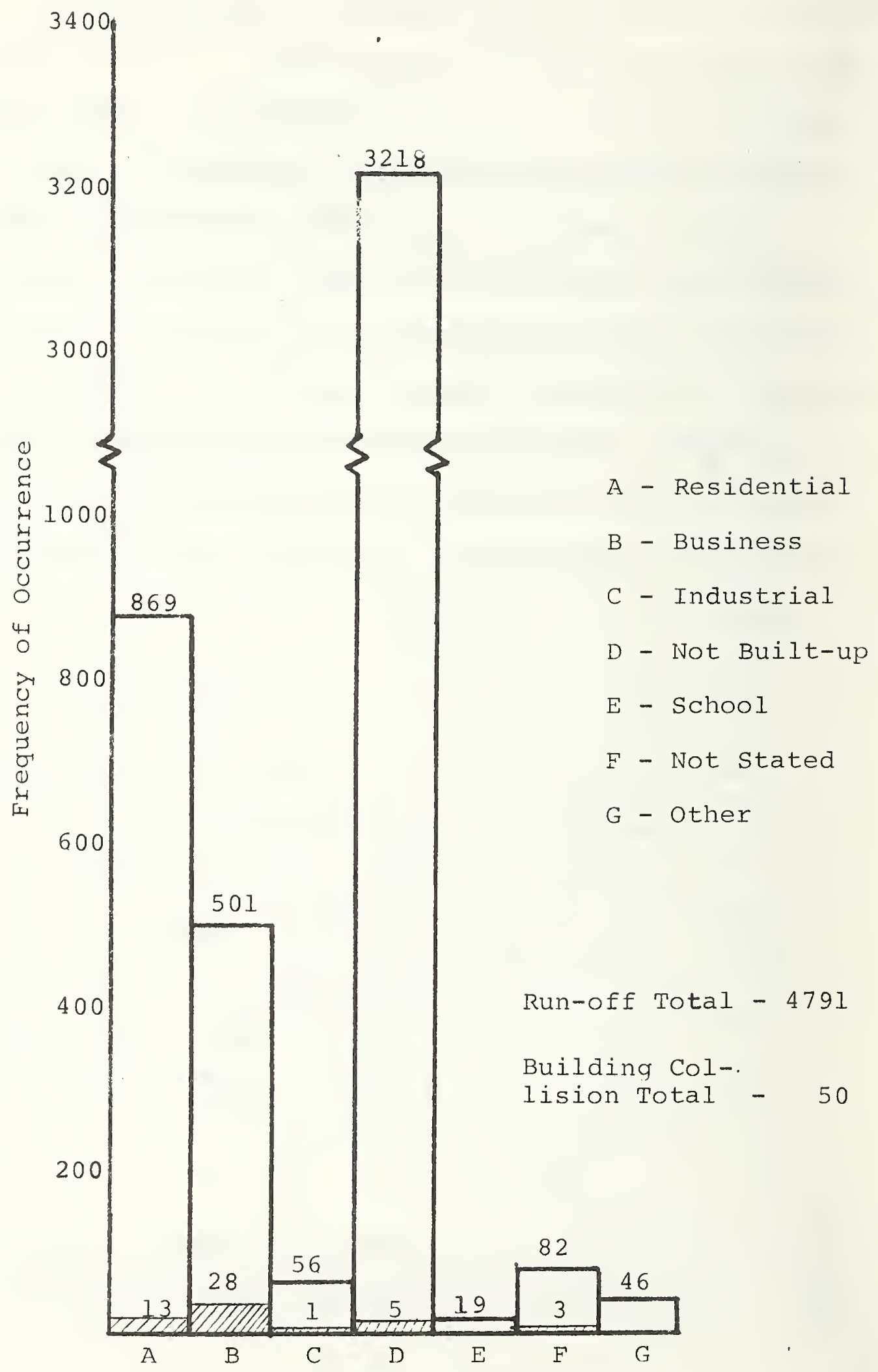

Figure A.I Run-off Accidents and Building Collision by Location 


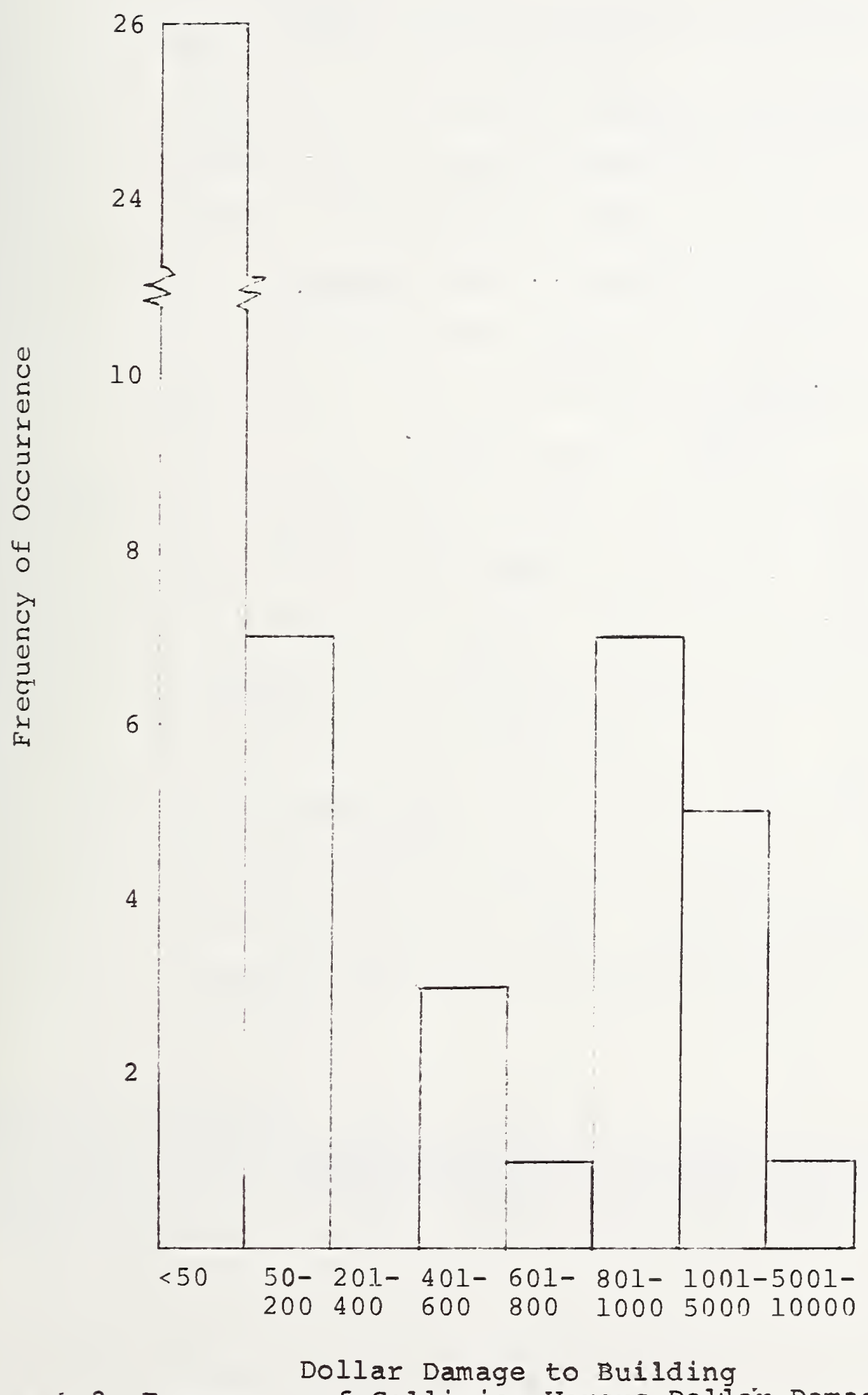

?. Fure A.2 Frequency of Collision Versus Doliar Damage to Building 
Frequency of Collision

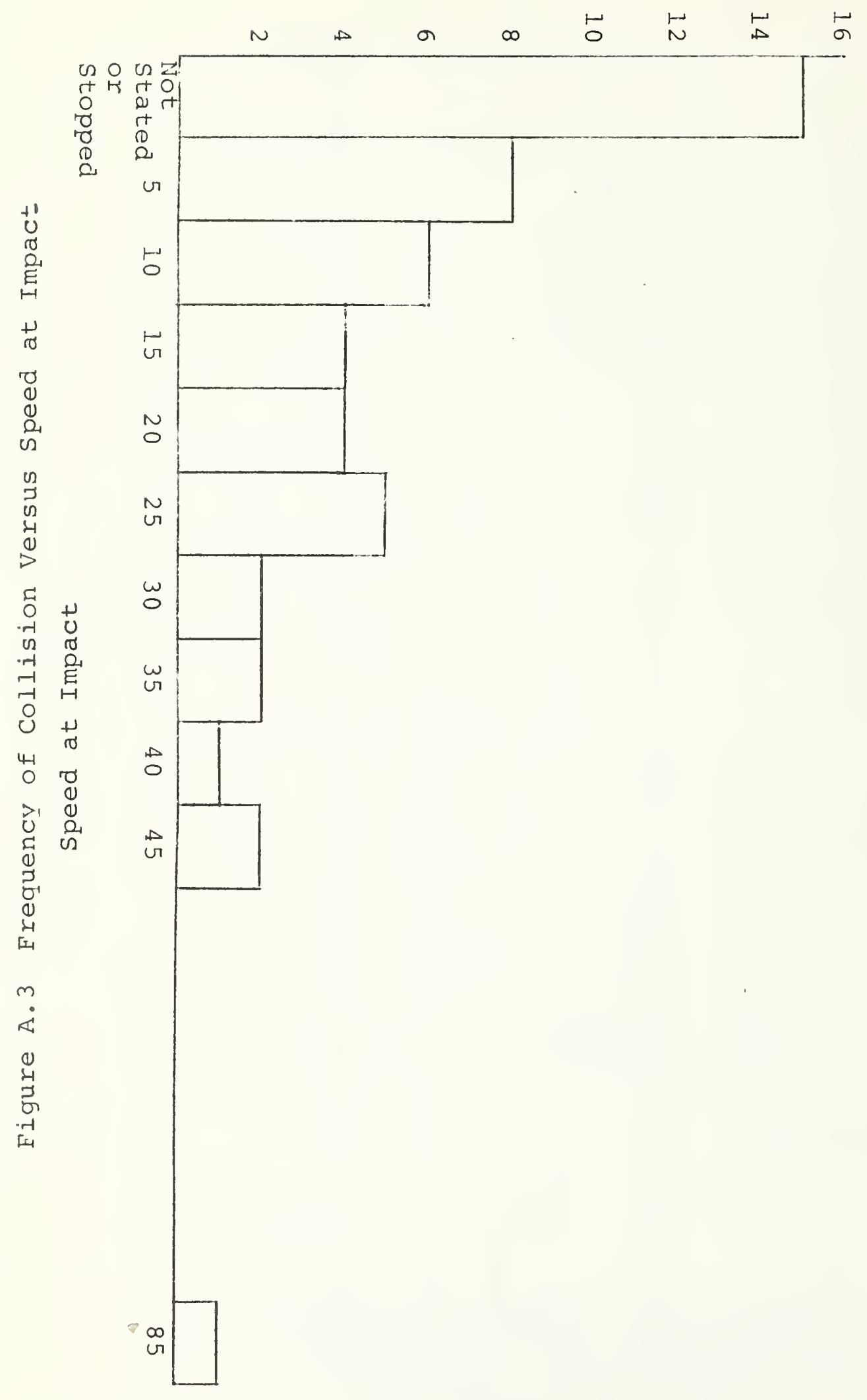


(3)* For built-up areas (defined in the Oklahoma Coding Guide to be business, industrial, residential or school areas) the fraction of the run-off accidents that were reported to hit a building was $42 / 1445=.029$. Average property damage in such areas was $\$ 585$, and the average speed at impactwas $11.5 \mathrm{mph}$.

(4) For a business area the fraction of the run-off accidents that were reported to hit a building was $28 / 501=.056$, with average property damage of $\$ 698$ and average speed at impact of $10.1 \mathrm{mph}$.

(5) For a residential section, the fraction of the run-off accidents that were reported to hit a building was $13 / 869=.015$. In this instance, average property damage was $\$ 194$, and the average speed at impact was. $12.7 \mathrm{mph}$.

(6) For an industrial section, the fraction of the run-off accidents that were reported to hit a building was $1 / 56=.018$. Average property damage was $\$ 2500$ and the average speed at impact was $35 \mathrm{mph}$.

\footnotetext{
The sum of accidents in built-up areas and non-built-up areas is less than the totals shown in (1) because 128 run-offs and 3 building collisions did not specify location. (See Figure A.1).
} 
It should be noted that each of the categories described above contains a very small number of accidents in which buildings were struck. The cited statistics must therefore be used with great care, especially since coding errors are considered to be not at all unlikely. In addition, speed and extent of damage were frequently left unreported, contributing further to possible unreliability of the average values shown. No meaningful correlation was found between speed, dollar darnage, and location of accident, but a far larger data sample would be required to verify the validity of this apparent lack of relationship.

Run-off and hit-building accidents were then separated by highway classification, as is shown in figure A.4. It should be noted that city streets were the scene of run-off accidents more frequently than any other type of road, while limited access highways (interstates and turnpikes) had significantly fewer reported. In addition, although only $32.6 \%$ of run-off accidents occurred on city streets, $76 \%$ of the total hit-building accidents took place on this type of road (where, of course, more buildings are to be found). Thus the probability that a building will be hit, given that a run-off accident has occurred on a city street, is estimated as $38 / 1561=.024$. The average property damage reported in such cases was $\$ 531$, and the average speed at impact was $14 \mathrm{mph}$. Not surprisingly, there were no accidents on interstate highways or turnpikes that involved hitting a huilitinr. 


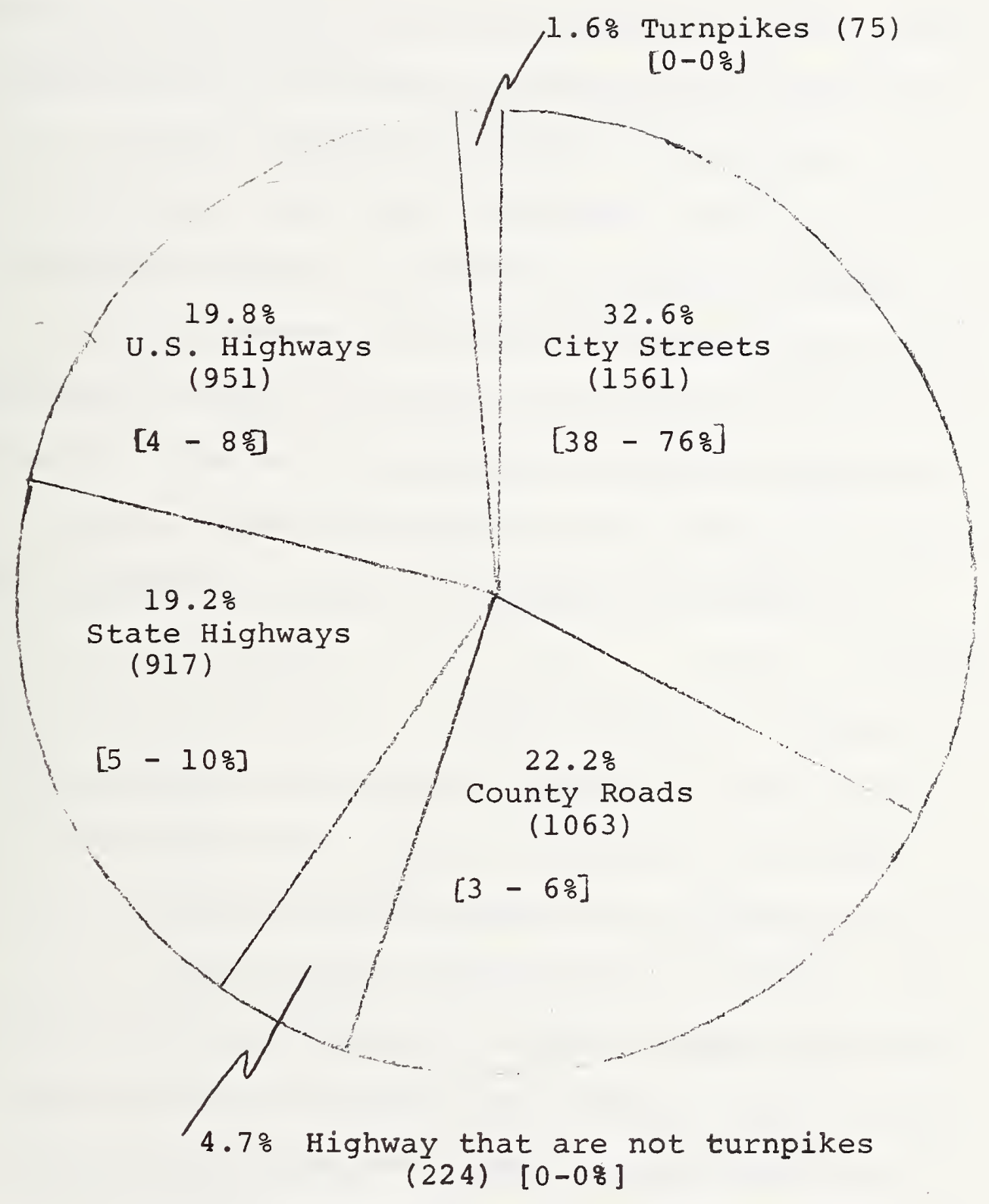

$(4791) *$ (OKLAHOMA, 1970) [50-100\%]**

* The number in parentheses is the total number of run-off accidents for that class.

**The numbers in brackets are the number of buildings hit for a highway class and the \% of the total buildings hit.

Figure A.4 Highway Classification for Run-Off Accidents 
Truck accidents were examined separately from automobile accidents. An accident involving a heavy truck, such as a semi-trailer, might do more structural damage to a building than would a car (given otherwise identical circumstances) due to the increased size and weight of the vehicle. A total of 423 accidents involving trucks were reported, including eight specifically listed as hitting buildings, The number of accidents involving the various types of trucks is shown in figure A.5. The high number of pick-up truck and single unit truck accidents is probably due to the large number of such vehicles compared to other truck types. The accidents considered in this histogram are coded as follows:

Code 1 - run-off road

Code 10 - collision on road with fixed object

Code 11 - collision on road with other object (excluding such objects as guard rails, other cars, utility poles, etc., which are specified in other codes).

These three types include all accidents where a building was struck. Truck accidents occurring in built-up areas were further broken down by speed at impact and type of truck. The results are shown in figure A.6. The percentages on the graph are an indication of the proportion of accidents occurring at higher speeds. The frequency of accidents where the truck was traveling at greater than or equal to $30 \mathrm{mph}$, or greater than or equal to $40 \mathrm{mph}$, should 
be noted, because a higher speed at impact combined with the heavier weight of a truck could cause considerable structural damage. In $1 / 3$ of the accidents within a given category the speed at contact was not reported, hence those cases were omitted from the percentage calculations.

In addition to the 50 vehicular accidents which were listed as having hit buildings, an additional 17 run-off accidents were considered as possible "building collisions." These all had listed a first-struck object of little value, but had reported total property damage greater than $\$ 800$. In all of these cases (65\%), the object struck was specified as "other". Further inquiry of the Oklahoma Department of Public Safety (which supplied the data) yielded no clue as to what this might indicate. A total of $94 \%$ of these possible "hit-building" accidents were on undivided highways and $61 \%$ were on roads with legal speed limits greater than or equal to $40 \mathrm{mph}$. The vehicle was traveling at speeds greater than or equal to $40 \mathrm{mph}$ in all specified cases, and greater than or equal to $30 \mathrm{mph}$ at contact in $83 \%$ of the specified cases.

Twenty-six individual accident reports were requested from the Oklahoma Department of Public Safety. The individual reports have a short summary and description of the collision, as well as a diagram of the scene of the accident. These reports provided information which had not been coded and hence was not on the computer tape. The 


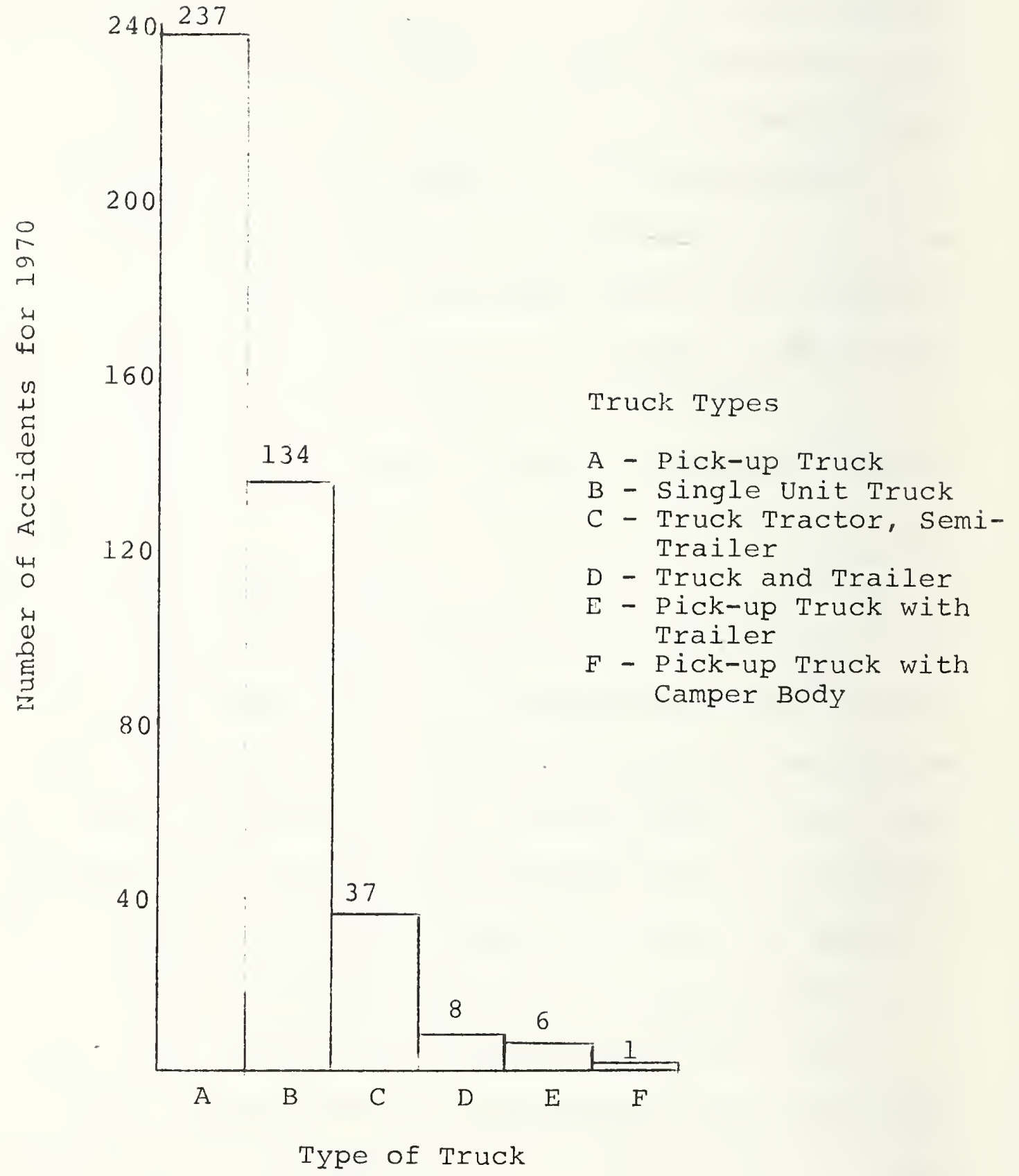

Figure A.5 Truck Accidents (Code 1, 10, 11) VS .

Type of Truck 


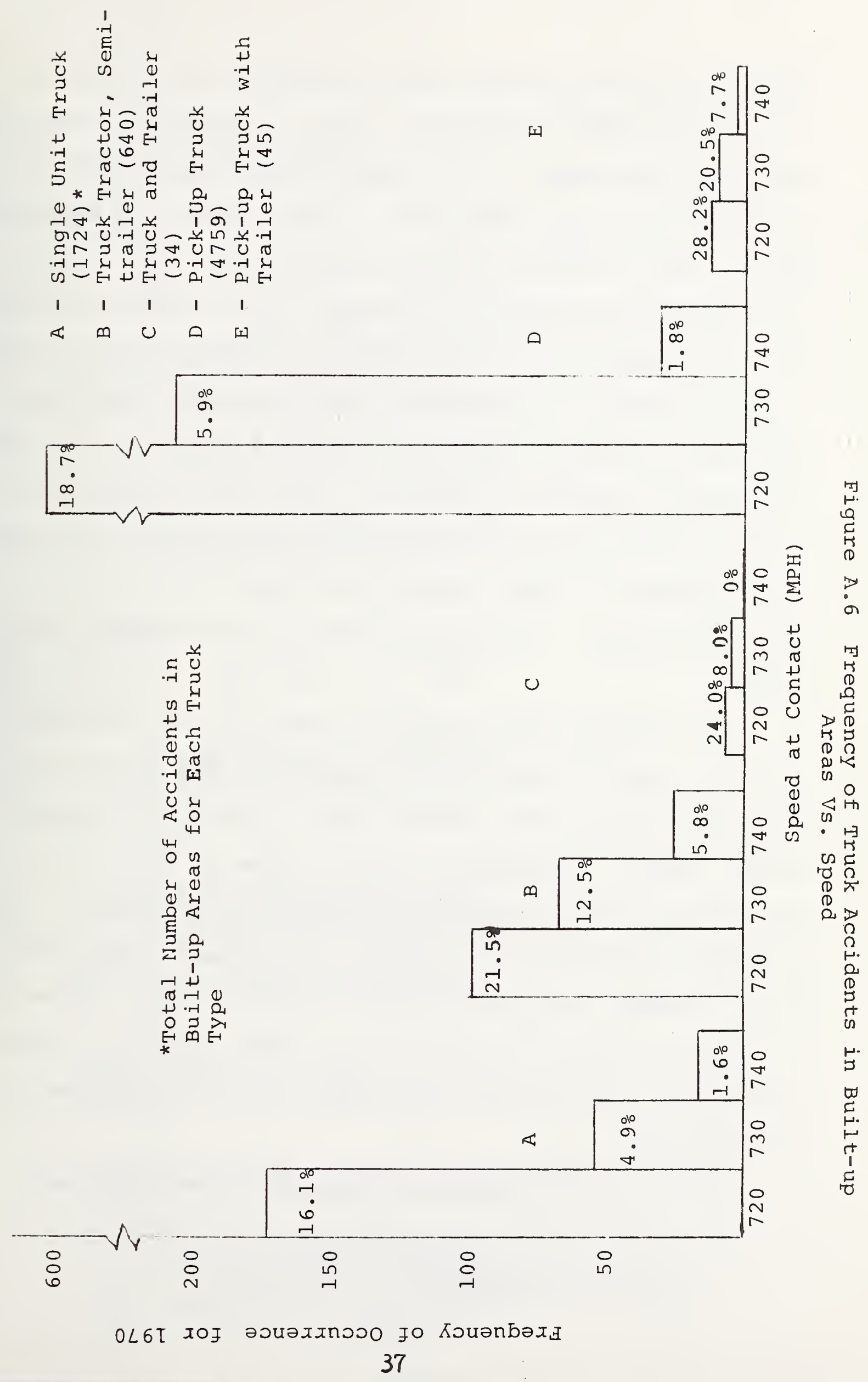


reports could be divided into 2 categories, the first of which (identified hereafter as Group A) includes 14 accidents which had been coded as collisions with buildings and which had involved damage (other than to the vehicle) in excess of $\$ 800$. Also in Group $A$ is one accident which involved four vehicles and a building, but damage to the building of only $\$ 50$. A summary of the information obtained from Group $A$ is shown in Table 1. A second set of 12 accidents (known as Group B) was chosen from those accidents referred to in the immediately preceding paragraph. These were accidents not coded as having involved collisions with buildings but which were suspected to have involved buildings due to high property damages. A summary of these reports appears in table 2 .

The diagram and descriptive summary of the individual accident reports permitted the derivation and analysis of data pertaining to the distance that the vehicle traveled before impact, the distance from the edge of the road to the object, and the physical location of the accident. The reported information was in many cases based on estimates only; in other cases no data was provided at all. Based on information gathered from the 14 accident reports in Group A (coded as having struck buildings), the following results are obtained.

(1) 13 of the accidents occurred on two lane roads, one on a four lane road; none of these was on a divided highway. 


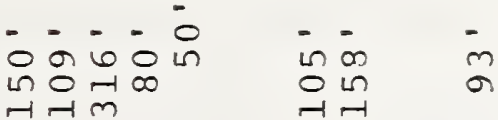

(1)

ט

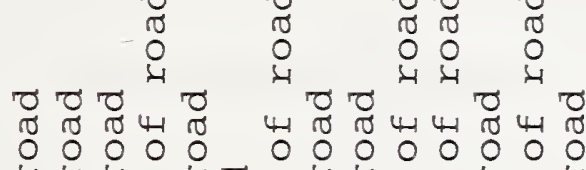

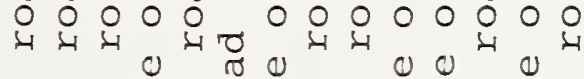
世山

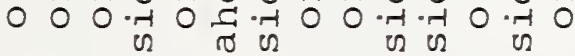

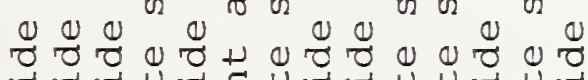

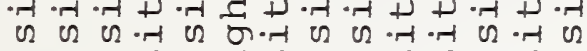

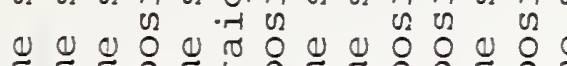

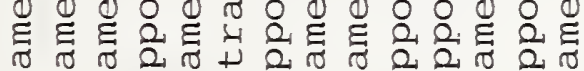
ル

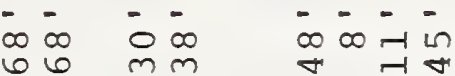

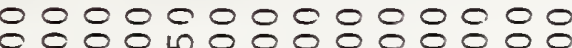
응의

i $\infty$ i

is $\infty+1$ m -1 त

(1)

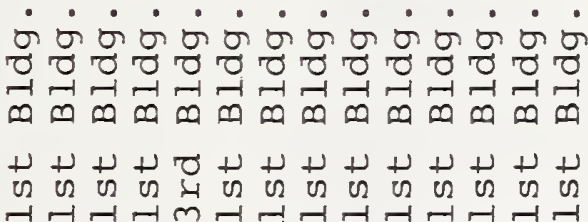

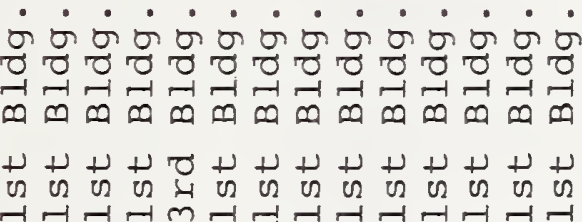

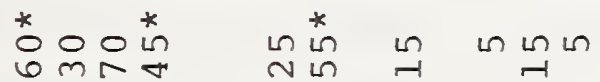

กา

$\Omega \infty U$

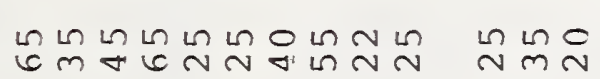

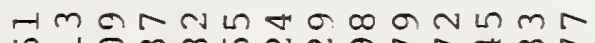
L HOM⿻

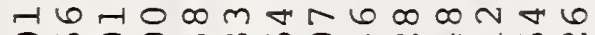
C L $00 \mathrm{~mm}$ L mNO-NRmm NGGNA 


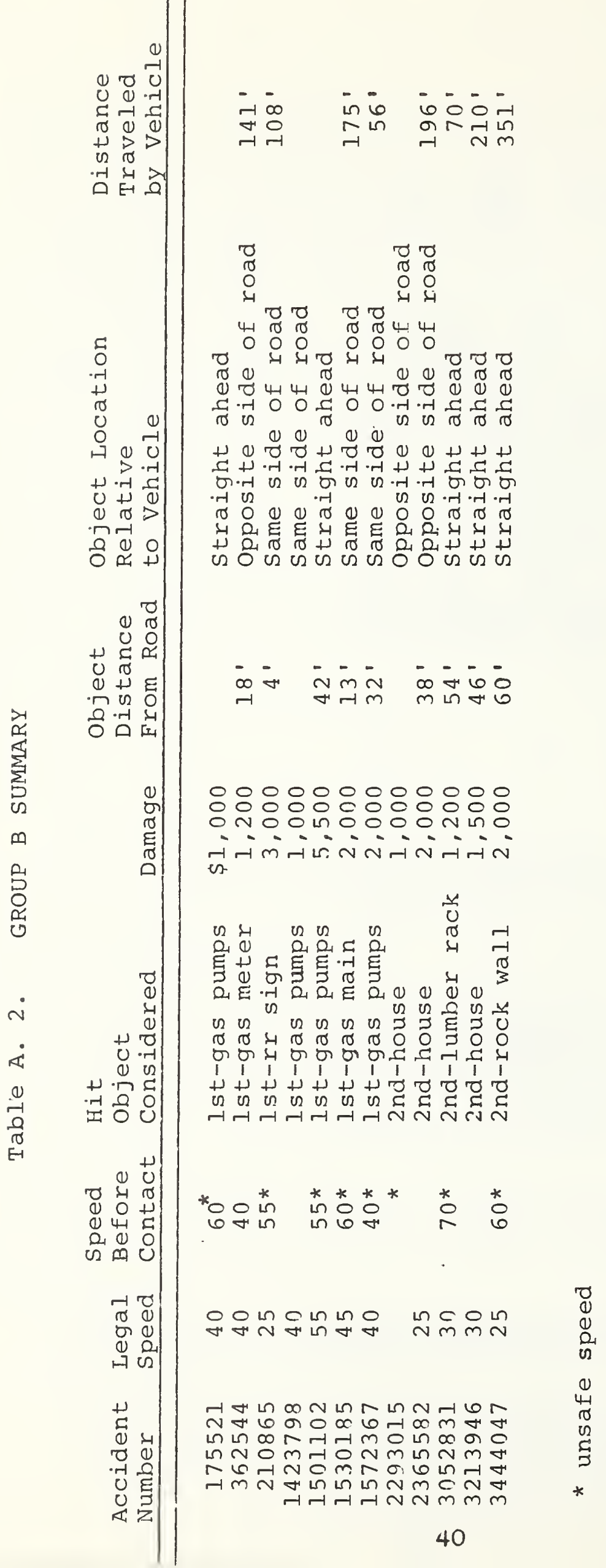


(2) 10 were on city streets, two on state roads, one on a county road, one on a U. S. highway.

(3) Nine occurred in business districts, two in notbuilt-up areas, one in industrial, one in residential, one not stated.

(4) Four took place in areas with less than 500 population, four in areas with greater than or equal to 100,000 population.

(5) 12 involved cars, one involved a tractor trailer, one a single unit truck.

(6) Five occurred on roads with legal speeds greater than or equal to $40 \mathrm{mph}$.

(7) Three involved unsafe speeds (marked with "*" on Figure 7) and four more did not specify "speed before contact."

(8) Seven accidents involved a building on the same side of the road as the vehicle, four on the opposite side, one straight ahead (across an intersection), one not stated.

(9) The average distance traveled by the vehicle before impact in eight specified cases was $132.6 \mathrm{ft}$.

(10) The average distance of the building from the road was $39.5 \mathrm{ft}$. in eight specified cases.

(11) There seems to be no correlation between distance the vehicle traveled before impact, or distance from the road to the building, and property damage. 
(12) Only one collision involved swerving to avoid another vehicle. Most were due to mechanical failure of the vehicle, or unsafe or negligent driving •

(13) One accident took place at a curve, seven occurred at or approaching intersections.

Although Group A constitutes a small sample, the information above does not vary significantly trom the statewide statistics. Items (7) through (13) provide information not on the computer tape.

The 12 accidents reports in Group B (coded as having hit something other than a building) yielded the following:

(1) Three of the accidents involved collisions with buildings where the building was not the first object struck. An additional accident involved a vehicle striking a large lumber rack.

(2) In four of the accidents, gas pumps were the first object struck; all four occurred in business districts and three accidents were on city streets.

(3) 10 of the 12 accidents occurred on city streets, one was on a U. S. highway, one on a state highway.

(4) Eight accidents occurred on two-lane roads, four on four-lane roads; none of these were divided highways. 
(5) Seven accidents took place in business districts, four occurred in residential areas, and one occurred in a not-built-up area.

(6) Five accidents were in areas with population greater than or equal to 100,000 , one in an area with population less than 500 .

(7) 10 involved cars. Two accidents involved pick-up trucks .

(8) Six took place on roads with legal speeds greater than or equal to $40 \mathrm{mph}$.

(9) Seven involved unsafe speeds.

(10) Three had the object struck on the same side of the road as the vehicle, three on the opposite side, four straight ahead (across an intersection or at a curve).

(11) The average distance the vehicle traveled before hitting the major object (building, gas pumps, etc.) was $163.5 \mathrm{ft}$.

(12) The average distance of the object from the edge of the road in eight specified cases was $34 \mathrm{ft}$.

(13) There seems to be no correlation between distances traveled, or object distance from the road, and property damage.

(14) Only one collision involved swerving to avoid other vehicles. Most resulted from mechanical failure of the vehicle, or unsafe or negligent driving. 
(15) Three took place at a curve, six occurred at or approaching an intersection.

Again, the information in this amall sample seems to follow the trend for the state as a whole. In addition to the four cases involving gas pumps, two others involved a natural gas meter and a natural gas main. This seems to account for many of the high damage value accidents with "other" coded as the first object struck. Many of the accidents in Group $B$ involved vehicles deflecting from traffic signs and making further contacts, or running through fences into other obstacles. It is significant that three of the 12 collisions examined involved buildings, suggesting that the estimated number of buildings hit in accidents, as derived from the coded tape, is low. The only way to determine how many additional buildings were struck would be to examine all of the reports, a task which is not feasible from the point of view of the time, effort, and cost which would be necessary.

\section{A. 3 Summary}

of a total of 65,183 accidents which occurred in Oklahoma in $1970,4,791$ or $7.3 \%$ were run-off accidents. Of the total run-off accidents, 50 or 1.18 are known to have involved collisions with buildings. $67.2 \%$ of the run-off accidents occurred in rural areas, but $76 \%$ of the known collisions with buildgins occurred in cities. The highest chance of hitting a building, given that a run-off accident 
has occurred, is in the business district; it is approximately .056. The highest average speed of impact ( $38 \mathrm{mph}$ ) and the highest average property damage $(\$ 800)$ occurs in non-builtup areas. The number of buildings coded as belng hit (50) is low, due in part, to the fact that an additional number of buildings were undoubtedly hit, but not reported because they were not the first object struck.

Using municipalities with a population of 5,000 as a breakpoint between urban and rural, 1,489 of the 4,791 runoffs can be classified as urban. Similarly, 32 of the 50 "building collision" accidents occurred in urban areas. The respective rural figures are 3,302 run-offs and 18 "building collisions." Of the 50 "building collision" accidents, six resulted in estimated damage in excess of $\$ 1,000$. Ot these six, one resulted in damage in excess of $\$ 5,000$.

It should be noted that a very small number of hitbuilding accidents occurred in each of the various subdivisions used above. Information on speed and damage was omitted frequently enough that the data were considered insignificant. Mistakes in coding are also a possible source of error. A correlation between speed, dollar damage, and location of the accident was sought, but not found to exist at a meaningful level. However, a larger data sample would be required to verify this apparent lack of correlation. Run-off and hit-building accidents were then separated by highway classification, as is shown in figure A.4. It 
should be noted that city streets were the scene of run-off accidents more frequently than any other type of road, while limited access highways (interstates and turnpikes) had significantly fewer reported. In addition, although only $32.6 \%$ of run-off accidents occurred on city streets, $76 \%$ of the total hit-building accidents took place on this type of road (where, of course, more buildings are to be found). Thus the probability that a building will be hit, given that a run-off accident has occurred on a city street, is estimated as $38 / 1561=.024$. The average property damage reported in such cases was $\$ 531$, and the average speed at impact was 14 mph. Not surprisingly, there were no accidents on interstate highways or turnpikes that involved hitting a building. Most non-passenger-car accidents involved pick-up trucks. Individual accident reports indicate that the average distance traveled by a vehicle after run-otf and before impact is $146.4 \mathrm{ft}$, while the average distance from the road of the struck object is $37 \mathrm{ft}$. In addition, slightly more collisions occur with objects on the same side of the road as the vehicle, and the fewest occur with an object straight ahead. Many collisions occur near intersections, and most are due either to mechanical failure of the vehicle or unsafe driving. Eleven of the 26 cases studied individually were based on collisions on roads where the legal speed was at least as high as $40 \mathrm{mph}$, and all 26 took place on undivided highways. 


\section{Appendix B}

\section{Illinois Vehicular Impact Analysis}

\section{B.I Introduction}

This chapter provides a statistical summary of building collision accidents which occurred in the State of Illinois during 1970. In conjunction with the Oklahoma data discussed in the previous chapter, it attempts to provide additional insight as to the nature of such accidents. Illinois motor vehicle accident records are very comprehensive, reporting up to three involvements for any vehicle in an accident. Thus, a vehicle which collides with a stop sign, for example, and then deflects into a building, will be coded as having done exactly that.

\section{B.2 Analysis}

According to state records, 409,174 motor vehicle accidents occurred in Illinois during 1970. Of these, 37,462 or $9.2 \%$ were recorded as run-off accidents. In turn, 1229 of these run-off accidents resulted in collisions with buildings. Building collision accidents accounted for $3.2 \%$ of the run-off accidents, or $0.3 \circ$ of all motor vehicle accidents recorded. However, motor vehicle accident records maintained by the state include only a fraction of the accidents which occurred in Chicago, namely those which occurred on state or U.S. numbered routes and/or those which resulted in fatalities. Of the 164,889 accidents 
which occurred within Chicago in 1970 , only 37,043 or $22 \%$ are maintained on state accident files. Therefore, the state accident statistics are biased downward as a result of this ommission.

B.2.1 Building Collision Accidents by Road Type

In figure B.1, the 1229 building collision accidents are categorized according to the type of roadway on which they occurred. As can be seen, 717 (or $58.3 \%$ of all building collision accidents reported) took place on urban city streets (category A). When the other urban categories ( $\mathrm{B}, \mathrm{C}$, and $\mathrm{D}$ ) are combined with this figure, the resultant proportion of building collision accidents which occurred in urban areas is 85\%, even with Chicago largely disregarded. This is reasonable since building collision accidents are likely to happen more frequently in built-up areas than in non-built-up areas. In addition, figure B.I indicates the low frequency with which building collision accidents happen on controlled-access highways. In all, only four reported building collisions resulted from motor vehicle accidents on controlled-access highways (categories $\mathrm{D}, \mathrm{E}$, and $\mathrm{H}$ ). This low incidence is probably due to a general paucity of buildings in immediate proximity to such highways, as well as safety features commonly found on many urban expressways. 


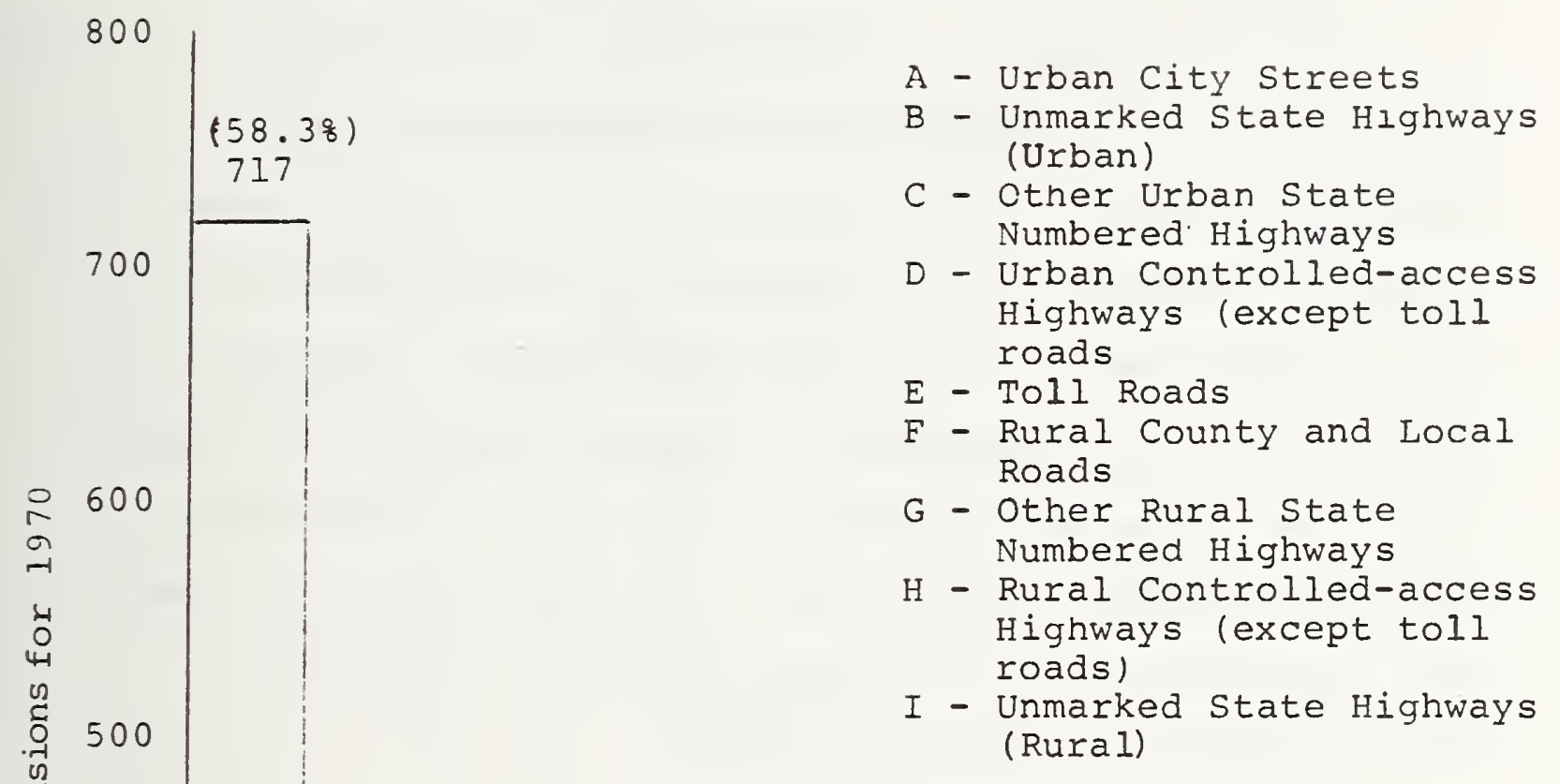

(9. 3ㅇ)

118

100

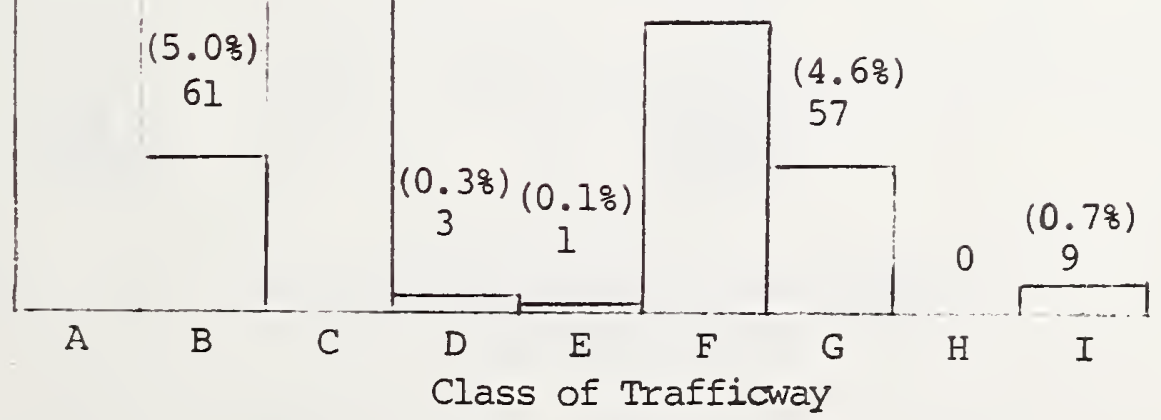

Figure B.2

Building Collision Accidents by Road Type 
B.2.2 Building Collision Accidents by Population

Figure B.2 depicts the distribution of "building collision" accidents by the population of the location in which the accidents occurred. The state of Illinois defines urban areas as "locations in or adjacent to a municipality or other urban areas of over 5,000 population." Therefore, using 5,000 as a breakpoint, it appears that $86.1 \%$ of the "building collision" accidents took place in areas with a population greater than 5,000. This agrees well with the 85 응 figure for urban "building collision" accidents calculated from the Oklahoma data.

B.2.3 Building Collision Accidents by Vehicle Type As shown in figure B.3, 1090 (88.7\%) of the "building collisions" were caused by automobiles; of the remaining $11.3 \%, 8.9 \%$ were caused by trucks.

Information was also available as to the number of vehicles involved in each accident, summarized in table B.l.

TABLE B.I DISTRIBUTION OF BUILDING COLLISION ACCIDENTS BY NUMBER OF VEHICLES INVOLVED

No. of

Vehicles

1
2
$>2$

TOTALS
No. of Bldg. Collisions

884

316

29

$1 \frac{29}{229}$
Percent

71.9

25.7

100.0 


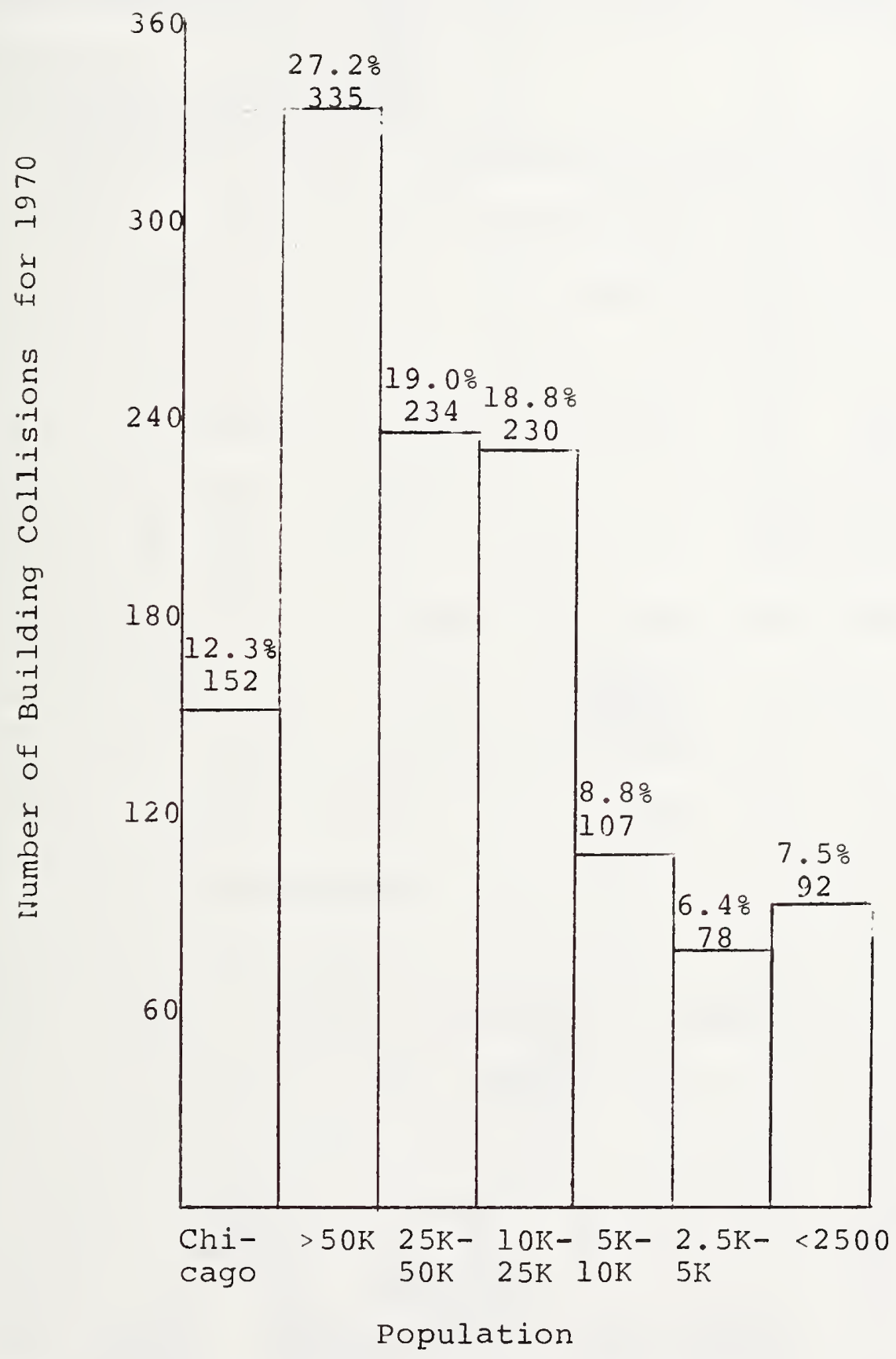

Figure B.2

Building Colliston Accidents

By Population 


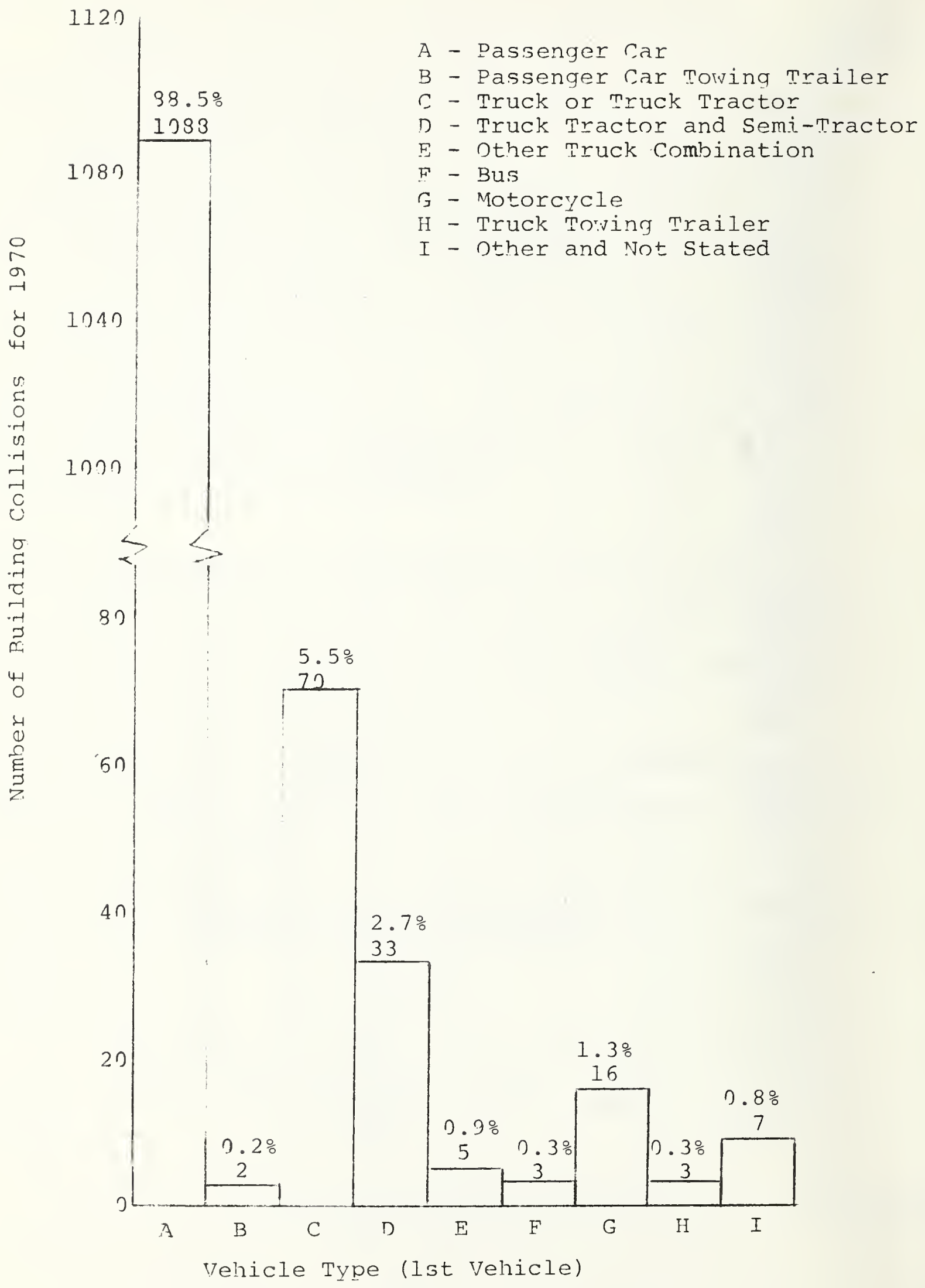

Figure B.3

Building Collision Accidents by Vehicle Type 
The table indicates that 884 of 1,229 accidents involved only one vehicle. Of these single vehicle accidents, 776 involved only passenger cars. Therefore, of the 1229 "building collision" accidents, 776 , or $63 \%$, involved a single automobile.

B.2.4 Building Collision Accidents By Dollar Damage to Property Figure B.4 displays the distribution of building collision accidents by dollar damage. This distribution is unfortunately incomplete, for of the 1229 accidents used as the base, only 558 (458), had damage estimates associated with them. There is no readily available information as to the methodology employed to estimate damage, in general or in specific incidents, nor as to whether the estimates are restricted to the damage done to the buildings. However, since all accidents in the data base are building collision accidents, an assumption that damage estimates refer only to damage done to buildings is not totally unreasonable. For the 558 accidents for which damage was reported, 343 were estimated to have caused less than $\$ 550$ damage. Of the remaining 215 accidents, 132 reported damage in multiples of $\$ 500$, leading one to believe that these estimates are little more than "ballpark" guesses as to the amount of damage incurred. Nevertheless, because the information is the best available, it is still useful to perform a cursory analysis in an attempt to gain additional insight as to the nature of building collision accidents. Furthermore, to the extent that damages may have been 


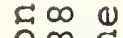

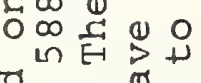

ro

(1) 4 ᄃ

$+0.10$

(1)

था द द

(1)

40 西

Q

(1) ro 0

4.

$14 \% \forall 0$

०ब 6 म

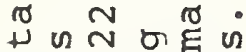

ब.

ठठ थ

10 \& $2 \cdot$.

(1) O O.H 10 \%

(1) $1+$ है $>\cdot$.

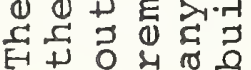
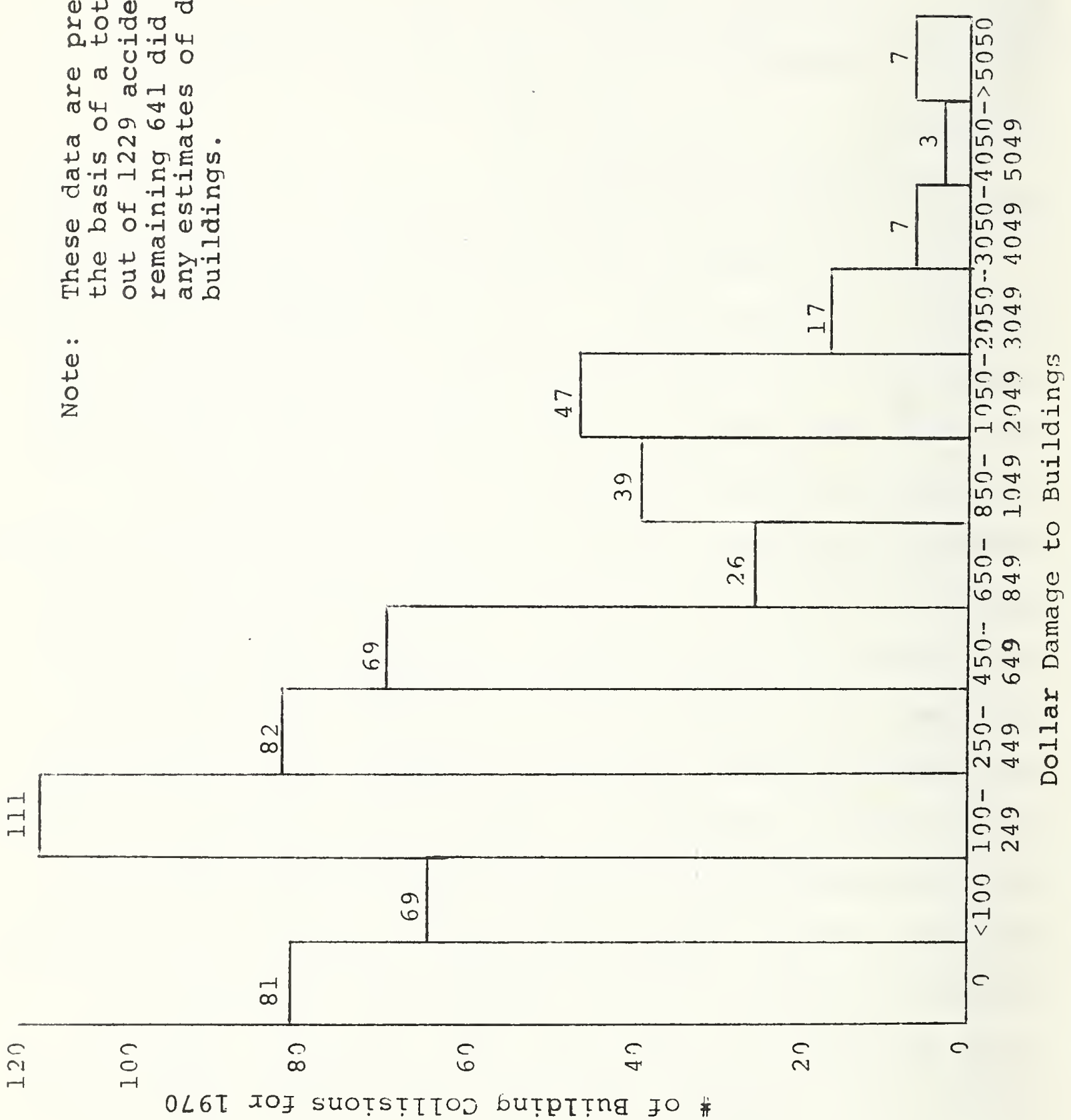

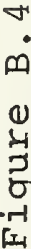


sustained by objects other than the buildings affected by collision, true damages are likely to be less than those reported and analyzed bo:low.

The average damage for the 558 accidents was calculated to be $\$ 667$. However, 412 (74\%) had damage estimates less than $\$ 650$, and the median for the damage distribution is approximately $\$ 300$. (The substantial difference between the mean and median can be explained by the occurrence of 6 accidents with damage estimated to be greater than $\$ 900$, tending to drive the mean upwards. In contrast, the occurrence of 261 accidents with estimated damage of less than $\$ 250$ tends to lower the median.)

A comparison of damage caused by trucks and that due to automobiles reveals some notahle differences. The average damage caused by trucks colliding with buildings was calculated to be $\$ 1,191$, although the median was approximately $\$ 300$. Mean damage for automobile accidents was calculated as $\$ 614$, or approximately half of the truck mean damage. However, the median for automobile accidents was also estimated at $\$ 300$. Certainly one would expect trucks to cause more damage to buildings than automobiles, because trucks have greater mass and therefore greater potential to cause extensive damage. 
The average damage was also calculated separately for urban and rural accidents. The mean damage for rural building collisions was computed as $\$ 833$, while the average damage for urban accidents was $\$ 618$. These figures were based on a sample of 125 rural accidents and 443 urban accidents, because there were only 558 accidents for which damage was reported. The rural accidents probably entail higher average damage because vehicles travelling on rural roads tend to be driven at greater speeds than vehicles on urban streets. It was decided to extract from the data base those accidents which had damage estimates of at least $\$ 3000$ and to submit these to further analysis. There were 24 such accidents. In table B.2, a few summary statistics derived from the sample are displayed in comparison to statistics gathered from the entire data base.

TABLE B.2 SUMMARY COMPARISON: MAXIMUM DAMAGE ( $\$ 3000)$ BLDG. COLLISION ACCIDENTS VS. ALL BLDG. COLLISION ACCIDENTS

Sample

Frequency Percent

No. in sample

Urban

Automobile

Single-Vehicle
24

16

17

16
100 응

$67 ㅇ ㅜ ㅇ$

$71 \%$

$67 \%$
Al1

Frequency

1229

1044

1090

884
Percent 1008 85 응 $89 \%$ $72 \%$ 
These results appear to be consistent with the mean damages discussed above: because urban accidents cause lower average damage than do rural accidents and because passenger vehicles do less damage than trucks, one would expect lower incidences of both automobile and urban accidents in a sample consisting of those accidents causing the most damage.

The frequency of single vehicle accidents in the sample does not appear to be significantly different from the frequency of single vehicle accidents for all building collision accidents. The occurrence patterns of the singlevehicle accidents were closely scrutinized in an attempt to observe general trenas. Of the total of 16 single vehicle accidents, 13 ran off the road and collided with buildings directly; the remaining three were deflected into buildings after first colliding with a highway sign, a utility pole, and a fence, respectively. Of these 16 accidents, 11 involved automobiles and five involved trucks. Only one of the truck accidents was a deflection. Based on this scanty evidence, it is difficult to draw any conclusions concerning the nature of major single-vehicle building collision accidents, although the data does seem to indicate that direct collisions occur more frequently than do deflections. 


\section{B. 3 Summary}

1) The analysis was based on a total of 1229 building collision accidents. These accidents constituted $3.2 \%$ of all run-off accidents and $0.3 \%$ of all motor vehicle accidents. However, the omission of $78 \%$ of the Chicago accidents introduces a downward bias to many of the results presented here.

2) 1058 of the 1229 building collision accidents (86\%) occurred in urban areas and, 58\% took place on city streets. Similarly, 21,537 of the 37,462 run offs are classified as urban.

3) Automobiles were the first vehicle involved in $89 \%$ of the building collision accidents, while trucks accounted for only 9 응

4) A single vehicle was involved in $72 \%$ of the building collisions. $63 \%$ of the building collisions were caused by a single automobile.

5) Only 45\% of the building collision accidents had damage estimates associated with them, with an average damage calculated at $\$ 567$. The average damage in truck-related accidents was $\$ 1191$, but automobile accident mean damage was calculated at $\$ 614$. The average building damage in rural accidents was $\$ 833$, whereas the average damage in urban accidents was $\$ 618$. Damage was estimated in excess of $\$ 1000$ in 113 accidents. Of those 113,10 carried damage estimates in excess of $\$ 5,000$. 


\section{APPENDIX C \\ Multistory Residential Buildings}

In Table 1, housing units for 1970 are partitioned according to the number of units per building. For example, the third row of the table can be interpreted as follows:

$$
\begin{aligned}
& \text { There are }(1.706) \times 10^{6} \text { owner occupied } \\
& \text { housing units located in buildings } \\
& \text { which contain } 2 \text { units per building. } \\
& \text { Therefore, these units account for } \\
& \left(\left(1.706 \times 10^{6}\right) \div 2=(0.853) \times 10^{6}\right. \\
& \text { residential buildings. }
\end{aligned}
$$

Those buildings which we assumed to be multistory residential are designated by a triple star. This information was taken from 1970 Census of Housing, Detailed Housing Characteristics, United States Summary, Table 22, and is shown on the following page. 
Table C.1' 1970 Housing Data

Units per

Building

Owner Occupied

1 detached

1 attached

2

3 and 4

5 or more

Mobile homes
Housing

Units $\left(\times 10^{6}\right)$ *

Buildings $\left(\times 10^{6}\right) * *$

$$
\begin{array}{r}
34.396 \\
1.112 \\
1.706 \\
.454 \\
.463 \\
1.751 \\
39.882
\end{array}
$$

$$
\begin{gathered}
34.396 \\
1.112 \\
0.853 \\
0.454 \\
<0.463 * * * \\
1.751 \\
\hline 38.335
\end{gathered}
$$

7.736

0.794

3.402

2.816

2.284

2.219

1.873

2.115

$\frac{0.321}{23.560}$

7.736

0.794

1.701

0.804

0.326

$0.153 * * *$

$0.054 * * *$

$<0.042 * * *$

$\frac{0.321}{11.931}$

0.571

0.407

0.571

0.135

0.194

0.028

0.494

$\frac{<.049 * * x}{0.783}$

65.108

* taken from 1970 Census of Housing, Detailed Housing Characteristics, United States Summary, Table 22

* calculated; all values are approximations due to varying size of class intervals.

*** assumed to be multistory buildings ( 4 or more stories) 
From the above information, the number of multistory residential structures (N) in 1970 is calculated as follows: $10^{-3} \mathrm{~N} \leqq 93,000+153,000+54,000+42,000+49,000=391,000$ The proportion of residential structures which are multistory $(P)$ is then calculated as follows:

$P \geq 391 / 51,049 \geq .008 \approx 18$

However, the estimated number of multistory residential buildings is somewhat questionable. In order to lend credibility to the estimate, an alternative procedure was performed using the number of residential units in structures with four or more floors. According to the 1970 Census figures, there are 3,295,304 residential units located in structures with four or more floors.* By making the extreme assumption that there are only four units per structure, the number of multistory residential structures is estimated as 824,000 . On the other hand, if the previous estimate of 391,000 is used, this would yield 8.4 as an average number of residential units per structure. This still appears to be low. Thus, the previous estimates of 391,000 appears to be a high estimate for the number of multistory residential structures in the United States in 1970.

Housing data for 1960 is given in table 2 .

1970 Census of Housing, Detailed Housing Characteristics, United States Summary, Table 24. 
Table C2. 1960 Housing Data

Units per Building*

Owner Occupied

I detached

I attached

2

3 and 4

5 or more

Mobile home
Housing

Units $\left(x 10^{6}\right)$ *

Buildings $\left(x 10^{6}\right) * *$

Renter Occupied

1 detached
1 attached
2 and 4
3 to 9
5 to 19
10 to 49
50 or more
Mobile home

1 detached

Mobile home

$$
\begin{array}{r}
28.436 \\
1.526 \\
1.443 \\
0.456 \\
0.258 \\
0.677 \\
\hline 32.797
\end{array}
$$

$$
\begin{array}{r}
28.436 \\
1.526 \\
0.722 \\
0.130 \\
<0.052 * * * \\
0.677 \\
\hline 31.543
\end{array}
$$

Vacant for Rent

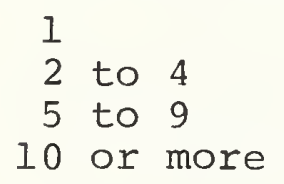

1

5 to 9

10 or more
7.891

1.860

2.683

2.343

1.770

1.141

1.283

1.165

$\frac{0.090}{20.227}$
7.891

1.860

1.342

0.669

0.253

$0.079 * * *$

$0.037 * * *$

$<0.023 * * *$

$\frac{0.090}{12.244}$

$$
\begin{aligned}
& 0.603 \\
& 0.378 \\
& 0.154 \\
& 0.291 \\
& \hline 1.426
\end{aligned}
$$

54.450

$$
\begin{aligned}
& 0.603 \\
& 0.126 \\
& 0.022 \\
& <\frac{0.029}{0.780}
\end{aligned}
$$

$<44.567$

\footnotetext{
* Taken from 1960 Census of Housing, Detailed Housing

Characteristics, United States Summary, Table 5.

** calculated; all values are approximations due to varying size of class intervals.
}

*** assumed to be multistory buildings (4 or more stories) 
Table C. 3 provides a summary comparison between the 1960 and 1970 figures.

Table C. 3. Summary Comparison of Hcusing Data 1960-1970

\begin{tabular}{|c|c|c|c|c|c|}
\hline & 1960 & 1970 & Change & 음 & Change \\
\hline $\begin{array}{l}\text { Multistory Buildings } \\
(\mathrm{x} 10 \mathrm{6})\end{array}$ & 0.220 & 0.339 & 0.171 & & $78 \%$ \\
\hline $\begin{array}{l}\text { Residential Buildings } \\
\quad\left(\mathrm{x} 10^{5}\right)\end{array}$ & $<44.567$ & $<51.049$ & $\approx 6.482$ & & $\approx 15 \%$ \\
\hline$\frac{\text { Multistory }}{\text { Residential }} \frac{\text { Buildings }}{\text { Buidings }}$ & $>0.005$ & $>0.008$ & & & \\
\hline $\begin{array}{l}\text { Multistory Units } \\
\left(x 10^{6}\right)\end{array}$ & 4.133 & 7.164 & 3.026 & & $73 \%$ \\
\hline $\begin{array}{l}\text { Housing Units } \\
\qquad\left(x 10^{6}\right)\end{array}$ & 54.450 & 65.108 & $10.65 \dot{8}$ & - & $20 \%$ \\
\hline$\frac{\text { Multistory Units }}{\text { Housing Units }}$ & 0.076 & 0.110 & & & \\
\hline
\end{tabular}

Basically, the figures indicate that in the 1960's, multistory housing had grown at a rate considerably faster than housing in general. Even so, in 1970, multistory buildings accounted for less than $1 \%$ of the residential buildings. However, these multistory buildings contained $59 \%$ of the 1970 housing units. 


\section{APPENDIX D \\ Motor Vehicle Registrations 1960-1970}

Table D. 1. displays the number of motor vehicles registered in the United States, as well as in the sample states of Oklahoma and Illinois from 1960 to 1970. Data are available at five year intervals for individual states and the U. S., and on a yearly basis from 1965 to 1970 only for the U. S.

Table D. 1. Motor Vehicle Registrations $\left(x 10^{3}\right)$ *

$$
\text { U.S. Okla. Ill. }
$$

1960

1965 .

$$
73,869
$$

1,184

3,776

1970

$$
90,358
$$

1,438

1,713

4,437

5,238

In Table D.2, information regarding the growth of motor vehicle registrations from 1960 to 1970 is provided. Table D. 2. Growth of Motor Vehicle Registrations 1960-1970 Difference $\left(\mathrm{x}_{10} 0^{3}\right) \quad$ \% Change Annual $\%$ Change $1960-1965$

$\begin{array}{lrrr}\text { U.S. } & 16,489 & 22.3 & 4.5 \\ \text { Okla. } & 254 & 21.5 & 4.3 \\ \text { Ill. } & 661 & 17.5 & 3.5\end{array}$

$1965-1970$

U.S.

Okla.

III.
18,078

275

801
20.0

19.1

18.1
4. 0

3. 8

3.6

$1960-1970$
U.S.
34,567
Okla.
529
Ill.
1,462
46.8
4.7
44.7
38.7
4.5
3.9

* Taken from Statistical Abstract of the United States 1971, Table 849 . 
These figures indicate that motor vehicle registrations have grown at the rate of roughly $4 \%$ annually throughout the 1960's. In order to obtain more precise annual growth estimates, the number of motor vehicle registrations should be presented for every year, rather than for every five years. Detail is available* for the United States as a whole but not for individual states. Table 3 presents the yearly registration data for the entire U. S. from 1965 to 1970.

Table D. 3. Motor Vehicle Registrations in U.S. 1965-1970* Registration $\left(x_{10}\right)^{3}$ Difference $\left(x_{10}\right)^{3}$ \% Change

1965

1966

1967

1968

1969

1970

$$
90,358
$$

94,193

96,931

101,039

105,097

198,436
3,835

2,738

4,108

4,058

3,339
4.2

2.9

4.2

4.0

3.2

According to the data in Table D.3, the average of the annual rates of growth of motor vehicle registrations in the United States between 1965 and 1970 is $3.7 \%$.

From Statistical Abstract of the United States 1971, Table 847 . 
FORM NBS-114A (1.71)

\begin{tabular}{|c|c|c|}
\hline $\begin{array}{l}\text { U.S. DEPT. OF COMM. } \\
\text { BIBLIOGRAPHIC DATA } \\
\text { SHEET }\end{array}$ & $\begin{array}{l}\text { 1. PUBLICATION OR REPORT NO. } \\
\text { NBSIR } 73-175\end{array}$ & 3. Recipient's Accession No. \\
\hline \multicolumn{2}{|c|}{ Fstimates of Vehicular collisions with Multistory } & 5. Publication Date \\
\hline \multicolumn{2}{|c|}{$\begin{array}{l}\text { Estimates of vehlcular collislons wlth liultistory } \\
\text { Residential Buildings. }\end{array}$} & 6. Performing Organization Code \\
\hline \multicolumn{2}{|c|}{$\begin{array}{l}\text { 7. AUTHOR(S) } \\
\text { Stuart I. Fribush, Deborah Bowser and Robert Chapman }\end{array}$} & $\begin{array}{l}\text { 8. Performing Organization } \\
\text { NBSIR } 73-175\end{array}$ \\
\hline \multicolumn{2}{|c|}{$\begin{array}{l}\text { 9. PERFORMING ORGANIZATION NAME AND ADDRESS } \\
\qquad \begin{array}{l}\text { NATIONAL BUREAU OF STANDARDS } \\
\text { DEPARTMENT OF COMMERCE } \\
\text { WASHINGTON, D.C. } 20234\end{array}\end{array}$} & $\begin{array}{l}\text { 10. Project/Task/Work Unit No. } \\
4374426 \\
\text { 11. Contract/Grant No. }\end{array}$ \\
\hline \multirow{2}{*}{\multicolumn{2}{|c|}{$\begin{array}{l}\text { 12. Sponsoring Organization Name and Address } \\
\text { Center for Building Technology } \\
\text { National Bureau of Standards }\end{array}$}} & $\begin{array}{l}\text { 13. Type of Report \& Period } \\
\text { Covered } \\
\text { Final }\end{array}$ \\
\hline & & 14. Sponsoring Agency Code \\
\hline
\end{tabular}

15. SUPPLEMENTARY NOTES

16. ABSTRACT (A 200-word or less factual summary of most significant information. If document includes a significant bibliography or literature survey, mention it here.)

Through analysis of data from oklahoma and Illinois along with national statistics, estimates are made of the number of vehicular collisions with buildings on an annual, nation wide basis. The best estimate is on the order of tens of thousands. However, since the impetus for the study was on multistory buildings and the likelihood of their being subject to progressive collapse the calculations have been refined to apply to substantial damage to multistory residential buildings. In 1970, such accidents were only on the order of 40 , hence the probability of a given building being so affected in a single year is approximately one in ten thousand. Some discussion is provided on improvement for data collection for the future.

\section{KEY WORDS (Alphabetical order, separated by semicolons) Collisions of vehicles with} buildings; multistory buildings; progressive collapse of buildings; residential buildings; vehicular impact.

18. AVAILABILITY STATEMENT

$\mathrm{X}$ UNL. IMITED.

FOR OFFICIAL DISTRIBUTION. DO NOT RELEASE TO NTIS.

\begin{tabular}{|l|l|}
\hline $\begin{array}{l}\text { 19. SECURITY CLASS } \\
\text { (THIS REPORT) }\end{array}$ & 21. NO. OF PAGES \\
UNCL ASSIFIED & 22. Price \\
\hline $\begin{array}{l}\text { 20. SECUR ITY CLASS } \\
\text { (THIS PAGE) } \\
\text { UNCL ASSIFIED }\end{array}$ & \\
\hline
\end{tabular}



